\title{
Exposición a Agroquímicos y Creencias Asociadas a su Uso en la Cuenca Hidrográfica del Río Morote, Guanacaste, Costa Rica: Un Estudio de Casos
}

\author{
EXPOSURE TO CHEMICALS AND BELIEFS ASSOCIATED WITH ITS USE IN THE MOROTE RIVER BASIN, GUANACASTE, \\ COSTA RICA: A CASE STUDY
}

Yendry Vargas Trejos

Investigadora y docente del Instituto de Estudios Sociales en Población, Universidad Nacional de Costa Rica. Heredia, Costa Rica.

\begin{abstract}
RESUMEN
Este artículo estudia la apropiación simbólica del agroquímico por parte de trabajadores agrícolas de la cuenca hidrográfica del río Morote en Guanacaste, Costa Rica. La forma cómo se apropia, percibe y experimenta el uso de estas sustancias se analiza considerando tres niveles de exposición al riesgo: la intuición del peligro en el entorno laboral, las vivencias de la intoxicación y el espacio de convivencia inmediato.

Por ser un estudio de tipo cualitativo sus principales fuentes provienen de la entrevista semiestructurada a cinco agricultores de comunidades rurales de la cuenca alta y media del río Morote, la aplicación de guías de observación y la georreferenciación espacial de su espacio de cultivo. Asimismo, la fotografía constituye un recurso valioso para establecer relaciones antagónicas entre lo que se dice y lo que se hace para evitar los peligros de la exposición al agroquímico. Entre los principales hallazgos del estudio se pueden mencionar tres destacables. En primera instancia, como agentes invisibilizadores del peligro por exposición se asumen las alteraciones a la salud por intoxicación como una situación común de la labor agrícola y como una manifestación de debilidad masculina.

Este punto nos lleva al segundo aspecto, ya que haber vivido experiencias de intoxicación modifica la percepción del agroquímico, principalmente entre los agricultores más adultos, quienes padecen hoy dolencias crónicas que asocian con la exposición prolongada a dichas sustancias.

El tercer punto evidencia que aun cuando se clasifica los plaguicidas como veneno, por sus impactos negativos en el ser humano y el ambiente, ningún agricultor expresa preocupación por residir con su familia de manera permanente en la zona agrícola y verse habitualmente expuestos a actividades de fumigación y fertilización.
\end{abstract}

(Vargas Y, 2015. Exposición a Agroquímicos y Creencias Asociadas a su Uso en la Cuenca Hidrográfica del Río Morote, Guanacaste, Costa Rica: Un Estudio de Casos. Cienc Trab. Ene-Abr; 17 [52]: 54-68).

Palabras Claves: AGROQUÍMICOS, RIESGOS LABORALES Y DOMÉSTICOS, SALUD HUMANA Y AMBIENTAL.

\section{ABSTRACT}

This article studies the farmer's symbolic appropriation of the agrochemical in Morote river's watershed in Guanacaste, Costa Rica. The way how they adapt, perceive, and experience the use of substances is going to be analyzed taking into account three different levels of exposition to the risk: intuition of the danger in the work's environment, experiences of intoxication and the immediate daily life space. This is a qualitative study, for that reason, the base of the information is provided by semi structured interviews to five local community farmers from the middle and low Morote river's watershed, as well as, the application of observation guides and the crops' spatial georeferencing. Photography is a valuable resource in order to establish opposite relationships between what is being said and what is really done for avoiding the dangers of being exposed to the agrochemical.

From the main results of the study, three are the most relevant. First of all, some are used as invisibility agents that hide the risk by exposition to the agrochemical and it is seen as a normal condition from the agricultural activity, as well as, a manifestation of male weakness. This will take us to the second point, because people who have being victims of intoxication, change their perception of the agrochemical, mainly elderly workers; who after years of working, are chronically ill and they relate that to the exposition to the toxic substances for many years.

The third point is evident when pesticides are classified as venomous substances, because of their negative effects in the environment as well as in human beings. None of the farmers living with their families permanently within the fields show any type of concern by being exposed to the fertilization and fumigation activities around them.

Key words: AGROCHEMICALS, DOMESTIC AND WORKING RISKS, HUMAN AND ENVIRONMENTAL HEALTH.
Correspondencia / Correspondence:

Yendry Vargas Trejos

Tel.: (506) 83747900 / (506) 24443808 /

Fax: (506) 25624262

e-mail: yvarga@una.cr / yendryvatre@gmail.com /

Recibido: 24 de Noviembre de 2014 / Aceptado: 08 de Febrero de 2015

\section{INTRODUCCIÓN}

La cuenca hidrográfica del río Morote se ubica territorialmente en la provincia de Guanacaste, específicamente en la península de Nicoya, la más grande del país. Con una extensión de $316 \mathrm{~km}^{2}$ esta cuenca comprende los cantones de Nicoya y Hojancha situados en su parte alta y media, y el cantón de Nandayure, localizado en el límite de su desembocadura.

Su pasado histórico sobresale por el asentamiento de la cultura indígena Chorotega proveniente de Tula, México (1000 y 1100 d. C). La 
única de influencia mesoamericana en Costa Rica y reconocida por el desarrollo de una agricultura intensiva. Los chorotegas cultivaban alternadamente maíz y frijoles, así como calabazas, algodón, chile, tabaco y cacao. Utilizaban el sistema de quemas para la preparación del terreno de cultivo, y fueron magníficos ceramistas y tallistas en piedra. ${ }^{1}$

Hoy el territorio de la cuenca está siendo impactado ambientalmente debido a tres problemáticas. Inadecuado uso y manejo del recurso suelo asociado con la incidencia de incendios forestales provocados, uso de agroquímicos, y cambios de uso del suelo de áreas con plantaciones forestales a producción intensiva de melón o a pastos para ganadería extensiva. Deficiente gestión del recurso hídrico, afectando los recursos bosque, suelo y agua, e inadecuada organización del sector agropecuario y forestal para potenciar el acompañamiento y el apoyo de los productores de toda la línea productiva. ${ }^{2}$

La situación ambiental de la cuenca ha estimulado desde el año 2009 el desarrollo de distintos proyectos de investigación y extensión comunitaria por parte de la Universidad Nacional. Se ha buscado atender de manera coordinada con las comunidades, el Ministerio de Salud y los gobiernos locales tres áreas de acción: la promoción de una cultural ambiental de respeto y conservación del río Morote, el saneamiento ambiental mediante la gestión de residuos sólidos y líquidos a nivel comunal, y la identificación de los riesgos humanos y ambientales que suponen las prácticas quimizadas del cultivo.

En cuanto a este último punto, en el año 2013 se inició un estudio de casos con cinco familias agricultoras residentes en las comunidades de Hondores (cantón de Nicoya) y Santa Rita (cantón de Nandayure), elegidas por su ubicación geográfica en la cuenca media y baja respectivamente, como lo muestra la Figura No 1, y por sus características productivas. Hondores, con una agricultura principalmente de autoconsumo basada en el cultivo de arroz, frijol y maíz; y Santa Rita con una agricultura asociada con la producción comercial del melón, sandía, maní y mango.
La cuenca actualmente presenta una superficie del $26,4 \%$ de bosque, y una predominancia de áreas de pastos $(41,3 \%)$, lo cual incrementa la vulnerabilidad a los incendios forestales en la época de verano. En la cuenca baja la expansión agrícola del melón y la sandía ha promovido el desarrollo de tecnologías agropecuarias ambientalmente poco sostenibles. ${ }^{2}$

El problema del uso inadecuado del recurso suelo no solo se basa en la divergencia de la capacidad biofísica natural del mismo (Mapa 1), sino en el limitado desarrollo de tecnologías agropecuarias para su manejo sostenible, lo que ha provocado una expansión agrícola en el cultivo de melón y la sandía en la parte baja de la cuenca. Se le suman las quemas, el crecimiento semi-urbano no planificado, la falta de iniciativas de reforestación con la modalidad de protección al ambiente, la limitada gestión de recursos, en especial de protección de suelo y del hídrico, y la inadecuada disposición de los desechos sólidos y líquidos, resultando perturbador para el entorno natural y social de la cuenca.

El estudio fue desarrollado con perspectiva histórica para determinar cómo se insertan en la dinámica productiva de la provincia de Guanacaste el uso de los agroquímicos, qué significados se construyen en torno a su manipulación, y de qué manera son percibidos sus impactos en el ambiente y las personas. En la provincia de Guanacaste, como en el resto del país, el uso de los plaguicidas se propagó a partir de 1950, para incentivar, en primera instancia, el desarrollo agrícola, y para satisfacer una demanda sanitaria, contribuir a prevenir enfermedades trasmitidas por diversos vectores. ${ }^{3}$

Empecemos explicando el primer objetivo práctico de la propagación de los insumos químicos en el país. Entre 1950 y 1970 Costa Rica experimenta un replanteamiento de su modelo de desarrollo económico, el modelo agroexportador basado en el monocultivo y la monoexportación del café estaba en crisis. Paradójicamente la actividad cafetalera se había constituido hacia 1940 en el epicentro

Fiqura 1. Mapa de ubicación del área de estudio.
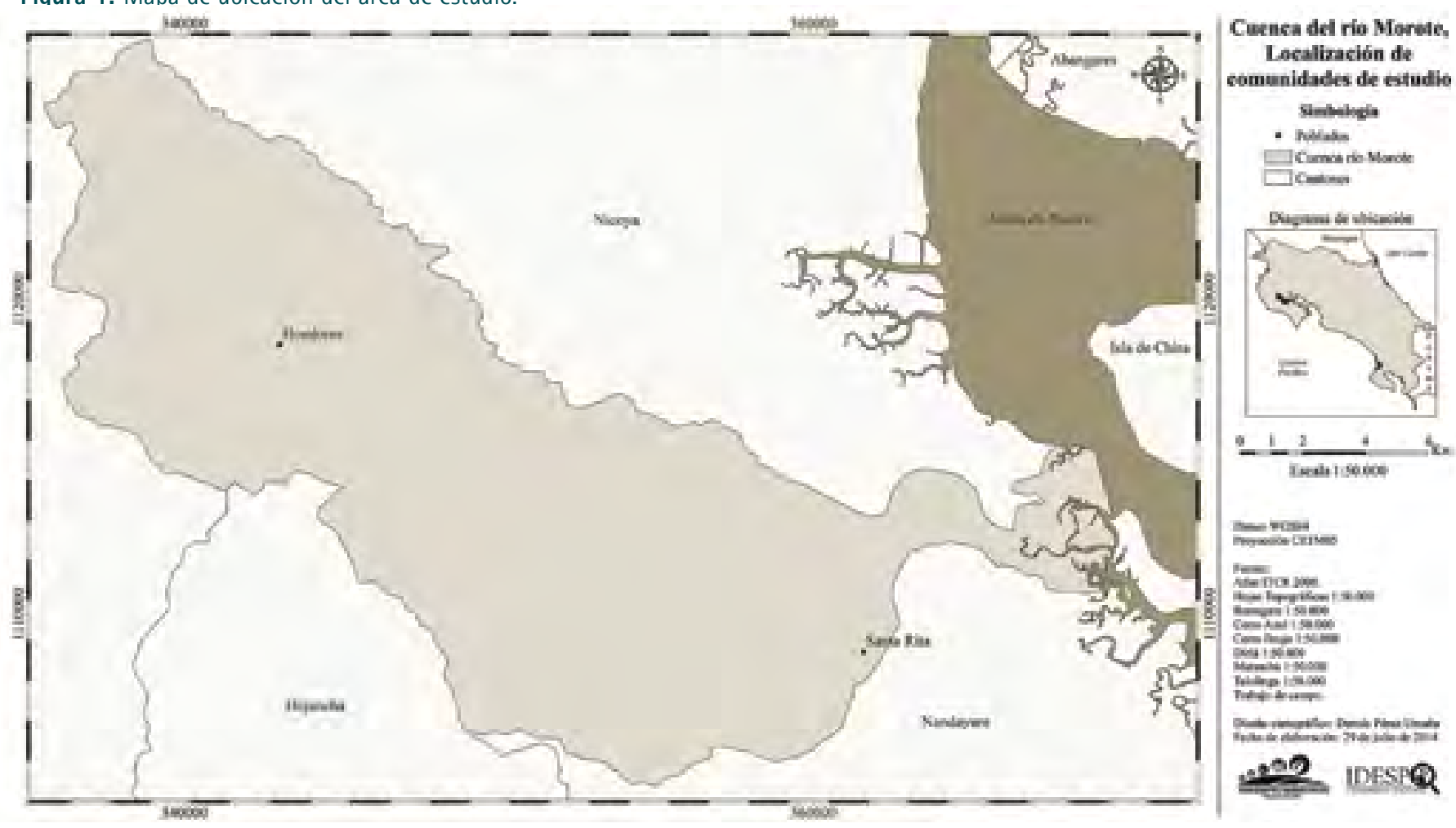
sobre el que giraba toda la economía, el progreso material y la vida social del país, pero también en el principal agente de subdesarrollo. Por su causa la economía nacional asumió un papel vulnerable dentro del contexto del sistema económico mundial. ${ }^{4}$

Ante esta situación se promovió la diversificación productiva y el desarrollo de la industria y la infraestructura material de la economía (electrificación, telecomunicaciones, carreteras, puertos y aeropuertos). Acciones que contribuyeron a un incremento en la producción del café, la caña de azúcar y el banano, así como del arroz y la actividad agropecuaria. ${ }^{5}$ Al finalizar 1990 la diversificación agrícola había transformado al sector agrícola costarricense en un sector dominado por la producción de monocultivos para la exportación, dependiente de insumos agroquímicos. ${ }^{6}$

En la provincia de Guanacaste estas acciones se materializaron en dos fenómenos particulares: el crecimiento económico y el impacto ambiental. El impulso técnico que recibió la producción de arroz, maíz y frijol convirtió a la provincia en el granero nacional. Las mezclas de plaguicidas y fertilizantes, mediante la aplicación terrestre y aérea, contribuyeron al aumento de los incrementos por hectárea $^{7}$; pero también favorecieron la erosión de los suelos ${ }^{8}$, la contaminación de las aguas y cuencas ${ }^{9}$, y claro está, incidieron en un incremento de los casos de intoxicación aguda por plaguicidas. En el periodo 1999-2002 Guanacaste alcanzó una de las más altas tasas de incidencia promedio de las intoxicaciones aguas por causa laboral reportadas en el país. ${ }^{10}$

Actualmente en la provincia el cultivo de los granos se alterna con la producción no tradicional de melón, mango, sandía, cítricos y caña de azúcar. En el caso de la cuenca hidrográfica Morote, la agricultura de autoconsumo basada en la producción de granos básicos y legumbres, coexiste al lado del cultivo de estos productos no tradicionales, así como la siembra de especies forestales (teca, melina, pochote) y pastos mejorados, la pesca artesanal y la ganadería de carne. ${ }^{2}$ En este momento existe la preocupación del uso intensivo que dichas actividades hacen de los insumos químicos, la forma en cómo agudizan la degradación ambiental y representan un peligro para la salud humana. ${ }^{11}$

Es así como desde entonces Guanacaste es reflejo de lo que acontece en el resto del país, ya que la producción regional, tanto como la nacional, dependen de la aplicación de una diversa gama de agroquímicos. De hecho, al iniciar el siglo XXI Costa Rica se posiciona como uno de los países a nivel mundial con mayor uso de plaguicidas por área agrícola. ${ }^{12-14}$

En este punto se amerita el abordaje del segundo objetivo práctico acerca de la propagación de los plaguicidas a nivel nacional, ya que junto con los discursos fitosanitarios que velaban por la sanidad de las plantaciones, se articulaban voces en procura de utilizar estos insumos en campañas de salud pública para prevenir brotes como el de la malaria. Entre 1950 y 1980 las provincias de Puntarenas, Guanacaste y Limón se constituyeron en la zona malárica del país por lo que el Dicloro Difenil Tricloroetano (DDT) se roció de manera intensa en cultivos, viviendas y comunidades. ${ }^{3}$ Aunque se erradicó con éxito esta enfermedad infecciosa, exámenes efectuados en 1980 en leche materna de mujeres residentes de dichas zonas, mostraban todavía la presencia del compuesto en sus organismos. ${ }^{15-16}$

La experiencia de estas mujeres expuestas al DDT evidencia de qué manera la exposición a estas sustancias puede impactar la salud humana. De alli que, tanto en Costa Rica ${ }^{17-20}$, como en América Latina $^{21-24}$, exista hoy abundante bibliografía que permite evidenciar y alertar acerca de los distintos efectos que la exposición a los agroquímicos tiene en la salud de hombres, mujeres y niños dedicados a labores agrícolas.

Es evidente que la manera en que los agricultores y sus familias conviven y manipulan cotidianamente las sustancias químicas implica riesgos de intoxicación y enfermedad crónica. En este campo investigativo médicos, psicólogos y antropólogos sugieren que una manera de comprender la problemática es analizando cómo se asume el riesgo de exposición, qué tipo de estrategias defensivas se desarrollan, y de qué forma el discurso social del más débil se sobrepone a cualquier medida de protección personal.

$\mathrm{Al}$ respecto, se han desarrollado estudios de casos en Argentina, Brasil, México y Costa Rica. Por ejemplo, mientras en el cinturón verde de la ciudad de Córdoba (Argentina), los trabajadores hortícolas conciben los plaguicidas no como veneno sino como medicina para las plantas ${ }^{25}$; granjeros expuestos a agroquímicos en un área rural del estado de Río de Janeiro (Brasil) minimizan el riesgo, niegan el peligro, y desarrollan estrategias defensivas para enfrentar el potencial dañino representado por sus actividades de trabajo. ${ }^{26}$ De esta forma, al elaborar una construcción social del riesgo de exposición a los plaguicidas, el agricultor continúa manipulándolos, y omite el peligro que representan para su salud. ${ }^{25}$ Además se fortalece la creencia de que el agricultor es de alguna manera "bendecido" por algún tipo de "gracia" que lo protege contra los efectos de la exposición. ${ }^{26}$

Estos discursos e imaginarios son los que explican que trabajadores rurales del estado de Chiapas (México), y agricultores del cantón de Nicoya (Costa Rica), eviten utilizar Equipo de Protección Individual (EPI). Entre los trabajadores rurales de Chiapas se suele comentar que solamente la gente débil y enferma resulta dañada cuando se exponen a plaguicidas. ${ }^{27}$ Por su parte, los trabajadores agrícolas de Nicoya se resisten a utilizar el equipo de protección requerido para aplicar los insumos químicos debido a las altas temperaturas de la zona. ${ }^{28}$

A partir de este contexto investigativo sobre percepción del riesgo por exposición a los agroquímicos, y considerando el escenario agrícola que actualmente predomina en la cuenca del río Morote, el presente estudio tiene el objetivo de conocer los factores de riesgo a los que se exponen agricultores de su cuenca media y baja. Se busca identificar el tipo de relaciones que en el entorno doméstico y laboral se establecen con los insumos químicos, para determinar cómo se interpretan los impactos humanos y ambientales de dicha exposición.

Las conductas de almacenaje, la convivencia cercana con el agroquímico, así como la experiencia de intoxicación aguda se conciben como indicadores que propician riesgos de impacto ambiental y humano. Los cuales a pesar de ser identificados por los agricultores, también son minimizados por estos, al considerar que la exposición al agroquímico efectivamente enferma y mata; pero tales efectos no tienen por qué repercutir en sus cuerpos, sus familias, o su entorno natural inmediato.

Desde tal perspectiva, en el contexto de la salud, los estudios de tipo cualitativo se convierten en una herramienta multidisciplinaria para interpretar cómo el sentido común del agricultor (significados, concepciones, representaciones, temores) puede dificultar la tarea de asumir responsablemente cuidados personales, la prevención de situaciones de riesgo para la familia y, por supuesto, la puesta en práctica de procesos de intervención para la atención integral de la salud humana.

Los retos que en este campo tiene el desarrollo de estudios con perspectiva histórica ambiental son suficientes como para empezar 
a investigar, por un lado, de qué manera la trasmisión oral de padres a hijos, desde la costumbre y la memoria, inciden en prácticas agrícolas que atentan contra la salud humana y ambiental. En tanto, por otro, el conocimiento histórico puede contribuir a implementar en el presente sistemas de cultivo de tipo orgánico, que aporten mayor calidad de vida a los agricultores y sus familias e impliquen un menor costo ambiental.

\section{MÉTODO}

La presente investigación consiste en un estudio cualitativo de tipo "estudio de casos", que se realizó con datos recolectados entre los años 2013 y 2014 para evaluar cómo en la cotidianidad de sus prácticas agrícolas los agricultores de dos comunidades de la cuenca hidrográfica Morote, en la provincia de Guanacaste, interiorizan e interpretan el riesgo por exposición a agroquímicos. Con la intención de hacer un análisis comparado de las percepciones de riesgo según espacios productivos y ubicación geográfica se estimó iniciar esta primera etapa investigativa con la selección de cinco jefes de hogar.

Los informantes fueron elegidos considerando tres criterios: a) haber sido los primeros de su núcleo familiar agrícola en adoptar prácticas quimizadas de cultivo, b) haber estado expuestos a este tipo de prácticas por más de veinte años, y c) haber experimentado más de un episodio de intoxicación personal o familiar por exposición laboral a agroquímicos.

El primer criterio de selección se justifica en la larga duración histórica. Como se ha indicado, en la provincia de Guanacaste el paquete tecnológico de la Revolución Verde se introdujo aproximadamente en 1950. Por lo que se eligieron varones, nietos e hijos de agricultores, que hubiesen nacido en estas décadas, para contextualizar, a partir de sus recuerdos, el momento en que sus abuelos, padres y ellos mismos, adoptaron las prácticas quimizadas de cultivo.

El segundo y tercer criterio de selección se argumentan en la historia de vida del agricultor. Se eligieron agricultores reconocidos localmente por sus prácticas quimizadas de cultivo, por reconocerse ellos mismos como individuos experimentados en el uso y la manipulación de los agroquímicos; y finalmente por estar familiarizados con los efectos de una intoxicación por exposición a estas sustancias.

Se buscó identificar, desde el relato de su historia vida, en qué medida un tiempo prolongado de exposición al agroquímico incidía en la percepción, vinculante o no, de los riesgos por exposición, y sus probables impactos en la salud. Asimismo, la experiencia de más de un episodio de intoxicación se consideró un indicador para determinar si en alguno de esos episodios se suscitaba un cambio de percepción en relación a la concepción del químico y los riesgos intrínsecos a su manipulación sin protección.

La información fue recolectada en cuatro etapas; en la primer etapa se visitaron las comunidades para registrar diferencias en las prácticas agrícolas, caracterizarlas según su ubicación geográfica, y establecer contacto con agricultores reconocidos localmente por su experiencia en el trabajo agrícola, y contar con terrenos propios para el desarrollo de sus actividades agroproductivas.

En la segunda etapa se eligieron los informantes claves y se aplicaron entrevistas individuales de tipo semi-estructuradas. Las temáticas de diálogo se organizaron en cuatro conjunto de preguntas. El primer conjunto de preguntas capturó información sociodemográ- fica del agricultor, en un segundo y tercer conjunto se analizó el tipo de actividades agrícolas desarrolladas en la zona de estudio, la adopción de las prácticas quimizadas de cultivo y sus aportes fitosanitarios. El cuarto conjunto investigó percepciones de riesgo, conductas de manipulación y almacenaje, y experiencias de intoxicación y sus probables efectos en la salud. Este instrumento puede ser consultado en el Anexo No. 1.

En la tercera etapa se estudió el espacio de convivencia inmediata con el agroquímico identificando el sitio de almacenaje y el área de cultivo como promotores de distintos escenarios de riesgo. Se estudió mediante al aporte de la georefenciación de dichos puntos, de qué manera la exposición humana, animal y ambiental en el entorno doméstico se relaciona con la cercanía existente entre el espacio de cultivo, el sitio de almacenaje del químico y la ubicación de la vivienda.

Un cuarto paso consistió en aplicar una guía estructurada de observación para investigar las características físicas de la bodega de almacenamiento y conocer la forma en que se dispone el agroquímico. Con base en las categorías de información establecidas en la guía de observación, se tomaron fotografías de cada uno de estos espacios. Por familia se estructuró un archivo fotográfico organizado según espacio de convivencia familiar, área de cultivo, sitio de descanso de animales, lugar de abastecimiento del recurso hídrico, $\mathrm{y}$ área de almacenaje. Este instrumento puede ser consultado en el Anexo No 2.

La información recolectada se representó cartográficamente ubicando el terreno de cultivo, la casa de habitación, la bodega, el sitio de descanso de animales y el pozo de agua. Por último, con ayuda del recurso fotográfico y del diseño gráfico, se reconstruyó el sitio de convivencia mediante el diseño de croquis de cada una de las fincas estudiadas.

En el estudio se recurre al relato expresado por los agricultores para describir y explicar sus experiencias laborales con los agroquimicos. Para interpretar la fuente oral se recurrió a las técnicas de análisis de discurso y construcción de categorias analíticas a partir de las cuales fueron organizadas las unidades significativas identificadas tratando de establecer vinculaciones entre ellas. Las categorías construidas fueron consideradas como la retórica discursiva de lo que se dice hacer para prevenir el riesgo.

Posteriormente, con ayuda de la observación en campo y la fotografía se trató de contrarrestar cómo se lleva a la práctica dicha retórica discursiva y a partir de qué acciones y actitudes se desarrolla la manipulación y el almacenaje del agroquímico. Las categorías analíticas elaboradas se describen en los siguientes párrafos.

\section{Apropiación simbólica del agroquímico:}

Esta categoría interpreta cómo se apropia el agricultor de las prácticas quimizadas de cultivo y de qué manera construye un significado económico y social del insumo químico. El primer valor simbólico se estudió categorizando los aportes y los beneficios (rendimientos en calidad y cantidad) que los agricultores suponen obtienen con el uso de estas sustancias.

El segundo valor simbólico se analizó a partir de los apelativos, las analogías y las comparaciones que se utilizan para referirse al agroquímico desde su contribución fitosanitaria y productiva, según sus potenciales daños al ambiente, y a partir de sus evidentes impactos en la salud humana. Las designaciones utilizadas de manera más reiterada se utilizaron como seudónimos para llamar a cada agricultor. 


\section{Conductas relacionadas con el uso del agroquímico en el espacio laboral:}

En esta categoría se analizan qué acciones desarrolla el agricultor antes, durante y después de aplicar los insumos químicos, y qué valoraciones intuitivas emite a través de sus sentidos para valorar el riego. Para cada agricultor se elaboró una matriz donde la información fue sistematizada en cuatro columnas: actitudes asumidas, valoraciones emitidas, sentidos involucrados y líneas representativas. Posteriormente se hizo una comparación por agricultor para identificar aspectos coincidentes y diferenciadores entre sus criterios.

La información se interpretó considerando dos escenarios: lo que se dice hacer y lo que en la práctica se hace. Para ello fue necesario analizar los relatos obtenidos mediante la entrevista oral a través de la observación en campo y la fotografía. Con tal fin los agricultores fueron observados en la práctica diaria de su trabajo agrícola mientras mezclaban y aplicaban insumos químicos.

\section{Imaginarios sobre la intoxicación por agroquímicos:}

Esta categoría considera los imaginarios expresados para explicar un episodio de intoxicación y sus efectos en el cuerpo humano. Se analizan las asociaciones que los agricultores establecen entre síntoma y malestar crónico para explicar qué conciben como una intoxicación por agroquímicos, mientras se estudian las percepciones de vulnerabilidad y superioridad física como agentes justificantes de por qué unos se intoxican y enferman, y otros no.

\section{RESULTADOS}

\section{"Cultivando la tierra", experiencias del trabajo agrícola}

La población entrevistada está conformada por cinco jefes de hogar con edades entre los 50 y los 70 años, costarricenses, originarios de la provincia de Guanacaste y formados en las labores agrícolas por sus padres y tíos. Todos ellos cuentan con un bajo nivel educativo, los mayores de 70 años no concluyeron su primaria, en tanto quienes sobrepasan los 60 años de edad cuentan con secundaria incompleta.

Para referirse a ellos se utilizan seudónimos que expresan la forma en que representan, simbolizan o categorizan al agroquímico. Para los jefes de hogar de Hondores se emplean los nombres de: Líquido, quien los denomina a través de dicho apelativo, Quemante, quien los concibe como sustancias capaces de quemar las malas hierbas y el cuerpo humano; y Fuerte, quien se considera un hombre fuerte por no haber sido nunca víctima de intoxicación.

Por su parte, a los agricultores de Santa Rita se les llama con los calificativos de Necesario, quien considera los agroquímicos insumos necesarios para alcanzar altos rendimientos por hectárea, y Peligroso quien los percibe como sustancias peligrosas, capaces de provocar cáncer, enfermar y matar a la persona.

Estos agricultores adquieren las parcelas donde viven a través de dos vías distintas. Líquido, Necesario y Peligroso son beneficiarios del Instituto de Desarrollo Rural (INDER), institución fundada en 1961 con el objetivo de redistribuir de manera equitativa la tierra para incentivar la producción en el territorio del país. Quemante y Fuerte son hermanos y obtienen el terreno a través de una herencia de su padre.

Líquido, indígena Matambú de 74 años de edad, padre de 6 hijos, aprende el trabajo agrícola al lado de uno de sus tíos, "El papá de nosotros, el que nos crió, fue un tío mío, él sembraba maíz, arroz y frijoles”. Hoy en su parcela de 10 has Liquido siembra estos mismos granos, así como algunas hortalizas para el consumo de la familia, "Yo aquí siembro el arroz, el maíz, los frijoles, también aquí había una tomatera de 400 matas, hemos sembrado pipian, pepino y vainica”.

La economía doméstica de la familia de Líquido se sostiene además con la cría de gallinas y cerdos; según recuerda, cuando los hijos estaban pequeños, a su esposa le regalaban los saltos de un toro, así llegaron a tener cerca de 9 vacas cuya leche formó parte de su dieta, "La lechita la usábamos en la casa, para lo niños". También tiene cultivadas 2 has de pochote que vende cuando hay demanda de madera en Nicoya.

Aproximadamente tres kilómetros distancian a Liquido de su vecino Fuerte, agricultor de 68 años de edad, padre de dos hijos y dueño de una parcela de dos hectáreas y media. Una de las imágenes que viene a su mente cuando recuerda la infancia es a su padre sembrado maíz, arroz y frijoles, "Mi papá toda su vida se dedicó a la agricultura, y nos dejó estas tierras para trabajarlas".

Fuerte cultiva maiz y arroz y, al igual que Liquido, su cultivo es para el autoconsumo, "El maíz lo produzco para el gasto de la casa y para los animales, si alguien viene le vendo, lo consumo aquí para no estarlo comprando". También tiene gallinas y bueyes que le facilitan la tarea de arar, "El pedacito de tierra cuando siembro arroz o rayo una tierra para sembrar maíz".

A unos $500 \mathrm{~m}$ del hogar de Fuerte, vive su hermano mayor Quemante de 70 años de edad, padre de 4 hijos, y dueño de una parcela de dos hectáreas y media, donde siembra maiz, arroz, pasto de corta, caña de azúcar y especies forestales como teca y pochote. Sus cultivos también son de autoconsumo, y como su hermano cuenta con unas pocas cabezas de ganado.

Necesario y Peligroso, como estos tres agricultores de Hondores, tradicionalmente han sembrado para el autoconsumo arroz, maíz y frijol, cultivándolos aprendieron la labor agrícola, Necesario recuerda: "Cuando era niño mi papá producía arroz, maíz y frijoles, eso hace unos cuarenta años", en su caso Peligroso menciona: "De pequeño yo, mi tío se dedicaba a la agricultura de arroz y maiz, y ahí aprendí”. Sus actividades de autoconsumo estos dos agricultores las han complementado con el cultivo de sandía, mango, maní y moringa, cuyo cosecha venden a intermediarios de la zona y de San José. Necesario, de 55 años de edad y padre de 5 hijos, siembra en su parcela de 6 has pipian, frijol, pasto de corta, sandía y maíz: "El maíz lo saco en elote y chilote, y lo vendo en Hojancha, La Mansión o Nicoya; la sandía la vendo a intermediarios de San José".

Peligroso, un año mayor que Necesario y padre de 2 hijos, alterna en su parcela de 6 has el cultivo de maíz, frijol, arroz y sandía, con otros como mango, maní y moringa. Sin embargo, considera que el Tratado de Libre Comercio que Costa Rica firma en el año 2009 con Estados Unidos ha afectado a los pequeños productores: "Ahora la venta de maíz aquí, en esta zona es mínima, uno siembra pero para el gasto, no hay venta, no hay comercio".

En los siguientes párrafos estos cinco agricultores expresan sus imaginarios, ideas y opiniones acerca del valor simbólico que el agroquímico tiene en su experiencia como trabajadores agrícolas y la manera en que lo manipulan diariamente.

\section{"El agroquímico es necesario"; saberes de su manipulación}

"Qué va a hacer uno, para que se dé la agricultura tiene que abonar, son necesarios", comenta Necesario al meditar en los aportes de los productos químicos que mejor conoce. Líquido observa beneficios en la manera en que contribuyen, con un menor esfuerzo, al control de la hierba, "Siempre hay que ocupar los líquidos, porque aquí la hierba 
es muy seria, hay buenos beneficios porque uno atrasa la hierba”. Quemante no recuerda el insumo que utilizaba para controlar la hierba, pero sí tiene claro sus efectos, y la forma en cómo, de alguna manera, aquel producto agilizaba el trabajo del machete: "Había uno para limpiar, el monte se aplacaba, entonces lograba usted más fácil para limpiarlo”.

Las mismas ventajas identifica Fuerte, para quien los agroquímicos facilitan su trabajo agrícola, ya que entre bomba de atomizar y tiempo existe una relación de conveniencia, "El beneficio que uno ve es que le ayuda a deshierbar la planta, lo que hago en un día con la bomba no lo hago con cuatro peones a medio día."

$\mathrm{Al}$ reflexionar en las razones por las que adoptaron los agroquímicos, también meditan en cómo aprendieron a utilizarlos, ya fuera mediante capacitaciones, asesorias técnicas, o desde su uso cotidiano. Necesario, Peligroso y Líquido aseguran haber participado en cursos y seminarios sobre manipulación de agroquímicos. Los hermanos Fuerte y Quemante indican no haber recibido capacitación sobre cómo manipularlos; fueron aprendiendo a través de la práctica.

El conocimiento adquirido en la manipulación del químico parece incidir en medidas preventivas como lectura de la etiqueta, búsqueda de recomendaciones al comprarlos, o solicitud de asistencia técnica de un ingeniero agrónomo. El sentido común también juega un papel importante, pues como expresa Fuerte: "Ya uno tiene la idea de cómo se trabaja, ya uno va ganando la idea”. Necesario, Peligroso y Fuerte afirman sentirse confiados cuando leen la etiqueta y siguen sus instrucciones. Al respecto, Fuerte explica: "ahí dice: 'Lea el panfleto primeramente antes de utilizarlo', y eso es lo que yo hago, leo el panfleto". No obstante, Líquido y Quemante advierten que por su dificultad de leer la etiqueta, debido a su nivel educativo, prefieren asesorarse en los sitios distribuidores de agroquímicos.

Líquido señala: "Yo de segundo no pasé, yo medio veo la etiqueta, yo le pregunto a un técnico”. De igual manera, Quemante agrega: "Yo no saqué ni el tercer año, yo pregunto al doctor que vende esas cosas". Por su parte, Necesario y Peligroso afirman que además de leer la etiqueta y pedir asesoría cuando compran el químico, acostumbran solicitar la visita de un técnico en agronomía y utilizar el programa que elaboran.

Cuando llevan a la práctica las recomendaciones recibidas estos agricultores valoran el riesgo de exposición al agroquímico y la necesidad de proteger su cuerpo a partir de tres indicadores. En primera instancia, consideran el tiempo de exposición para medir el riesgo a intoxicación. Necesario opina que no utiliza guantes ni botas, "Porque tal vez hacemos uno o dos aplicaciones al día, y los productillos que uno usa son livianos".

El mismo argumento emite Fuerte: "Hay productos que usted los usa un rato, digamos una manzana usted la abona como en dos horas". Un segundo indicador es la molestia dérmica que el contacto directo con el químico provoca, o bien cuando su olor es intenso. En relación al tacto, Fuerte explica, "Yo llevo un balde y con la mano voy aplicando, si usted tiene un granillo por ahi, pues tal vez le quemó un poquillo".

En aspectos de olfato Líquido reconoce haberse sentido, en algunas ocasiones, molesto debido al olor de los insumos aplicados: "El líquido no le hace daño a uno, pero si agarra el cernido". El tercer indicador valorado corresponde a las medidas de seguridad asumidas para cuidar las distintas vías a través de las cuales el químico podría ingresar al organismo.

Tal es el caso del consumo de alimentos cuando se manipula la sustancia, o bien el tiempo que se permanece vestido con la ropa utilizada durante su aplicación. Líquido señala la importancia de evitar ciertas prácticas: "Hay muchos que andamos con la boquilla abajo y con el cigarrillo en la boca y eso es malo porque se intoxica rápido".

No obstante, en la práctica del trabajo agricola existen trechos entre lo que se dice, y lo que se hace para evitar una intoxicación, en las siguientes líneas se analizan las percepciones y las prácticas que se activan para prevenir el riesgo.

\section{"El agroquímico no me hace daño"; trechos entre el decir y el hacer}

A pesar de que estos agricultores conciben a los agroquímicos como "líquidos tóxicos", "quemantes contaminantes", y "químicos peligrosos" debido a su potencial de intoxicar al ser humano y dañar el ambiente, la negación del peligro se pone en juego cuando se sale al encuentro del riesgo. Es así como resulta habitual evitar el equipo de protección personal, manipular de forma directa el agroquímico, y considerar que unos son propensos a sufrir una intoxicación y otros no.

Liquido opina: "Los líquidos que uno riega, todos son tóxicos". Peligroso enfatiza el daño humano al sugerir que según su toxicidad, los agroquímicos provocan cáncer: "De aquí cercano, aplicando químico en una melonera de etiqueta roja, un muchacho se

Figura 2.

Aplicación de fertilizante en una plantación de maíz.

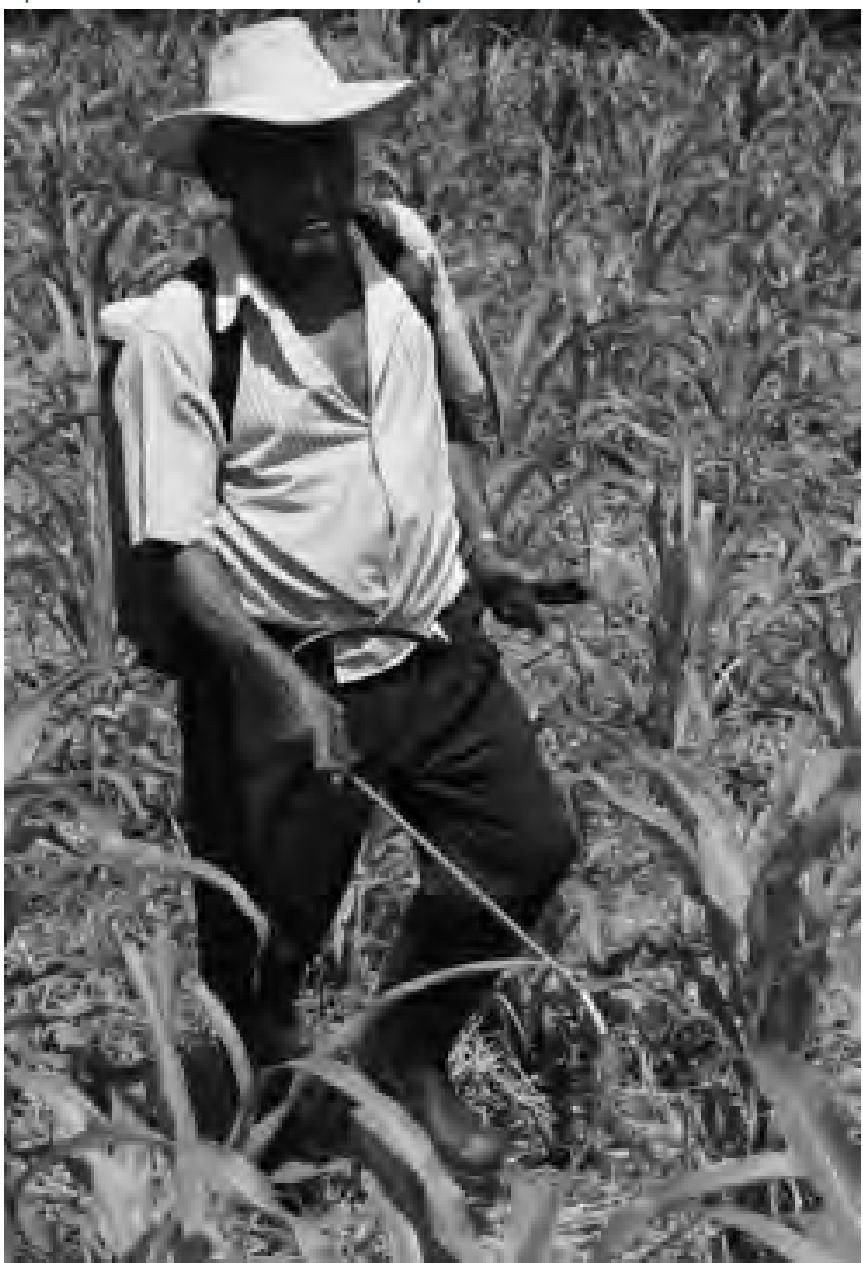

Los cinco agricultores entrevistados aplican los agroquímicos entre 5:30 y 10:00 a.m., pues consideran que en estas horas el suelo los absorbe mejor. 
Figura 3.

Mezcla de plaguicidas para el control del gusano cogollero.

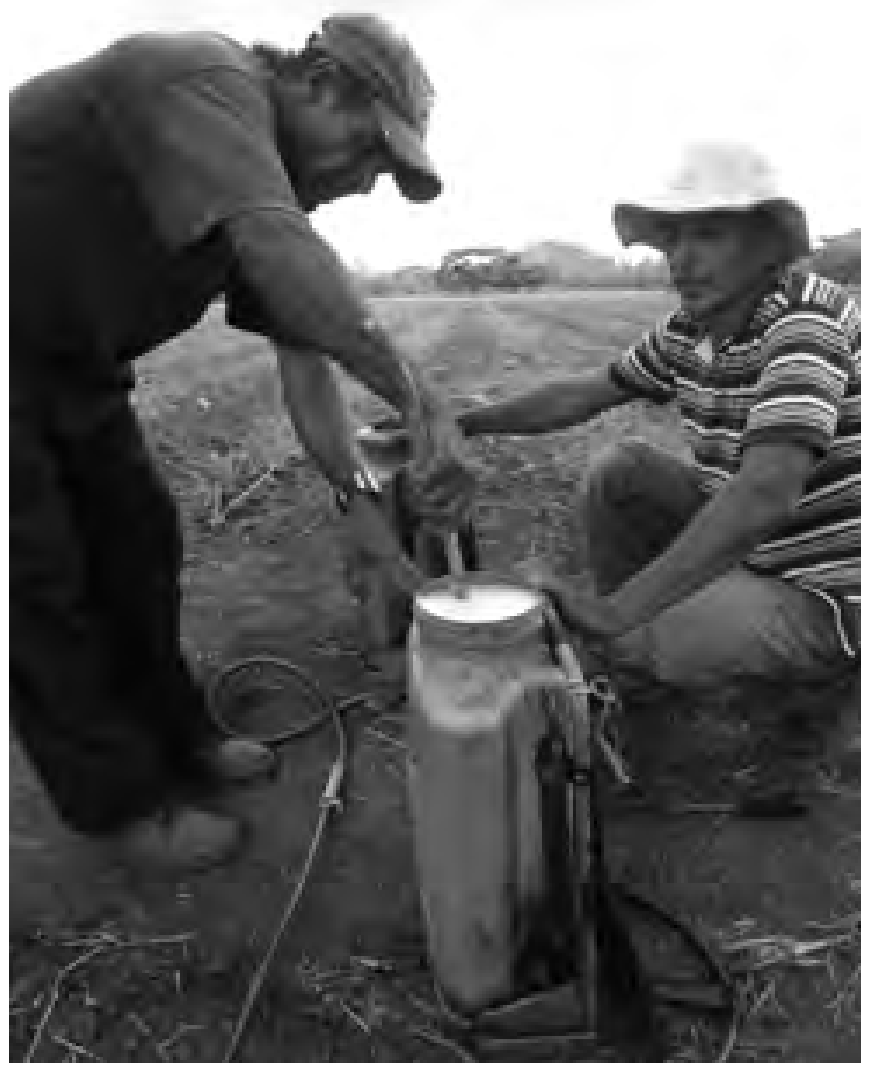

Las mezclas se hacen al aire libre y en un sitio distante de la casa de habitación, también se cuida la dirección del viento al momento de realizar la aplicación.

enfermó de cáncer de páncreas, la etiqueta roja va directo a matar". Por los efectos humanos que pueden causar, Necesario considera que "los agroquímicos no son buenos, si se puede usar algo orgánico es mejor". Por el contrario, Fuerte piensa que el daño humano que ocasionan estos insumos se asocia a temores de la persona: "La gente tiene la idea de que los agroquímicos le puede hacer daño, por eso se enferman cuando los riegan".

También se expresa con claridad el impacto de los agroquímicos en el ambiente, los cuales están asociados con la contaminación del suelo. Líquido, Fuerte y Quemante establecen de forma directa estas interrelaciones. Para Fuerte resulta particular cómo los agroquímicos contaminan el entorno natural que no fue directamente fumigado: "Si yo echo aquí, y usted tiene un árbol allá, cuando son ocho dias ese árbol tiene las hojitas dormidas, no se muere, pero se le ponen las hojitas achicharradas que llama uno".

Quemante recuerda que siendo peón agrícola solia poner atención a los efectos de la fumigación: "Caían bichillos porque el herbicida jode más la tierra, tal como ese Gramoxone". Aun comprendiendo la manera en que el agroquímico enferma al ser humano e impacta al ambiente, estos agricultores asumen distintas estrategias defensivas para lidiar con el riesgo de exposición a los insumos químicos.

En la rutina del trabajo agrícola es habitual que ninguno de ellos utilice equipo de protección personal cuando los insumos se mezclan, se realiza su aplicación o se limpia el equipo usado, como se observa en las Figuras № 2, No 3, No 4 y No 5. No existe diferencia en la percepción de peligrosidad, según sea una bomba de
Figura 4.

Proceso de mezcla de herbicidas para su aplicación en pastos mejorados.

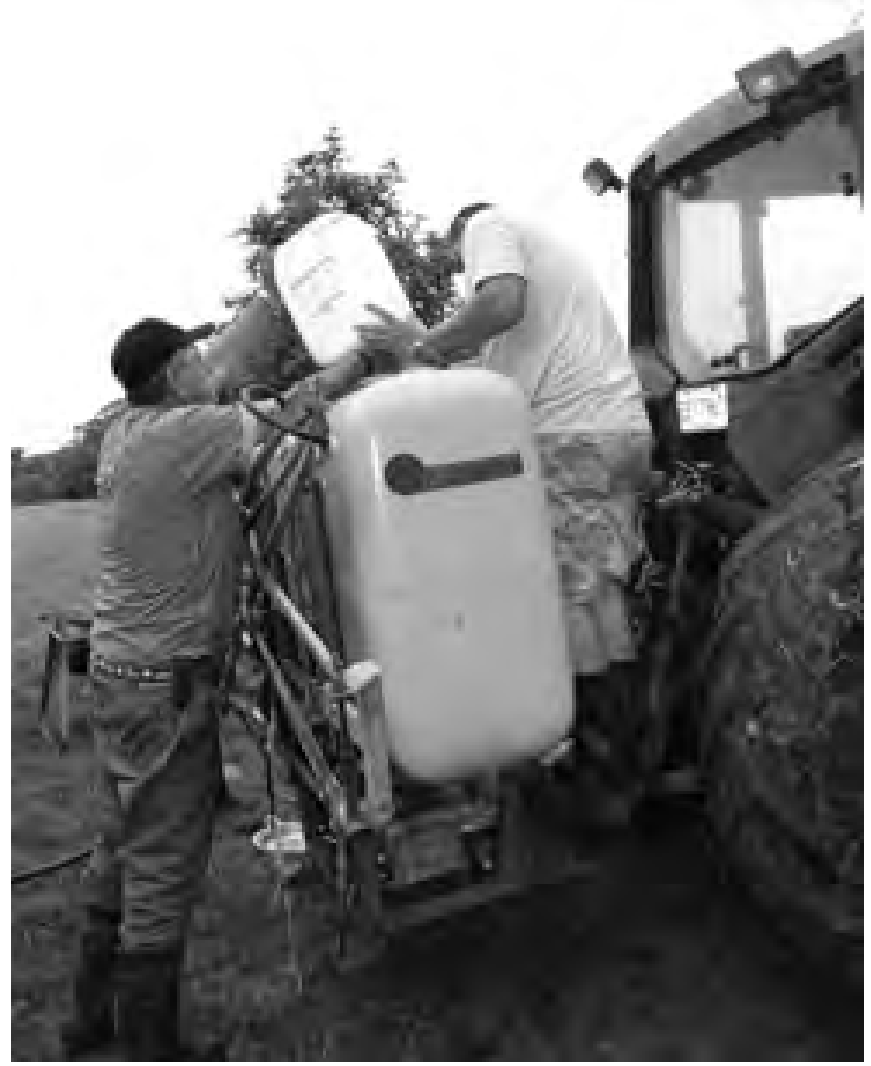

Cuando se contratan servicios de un aplicador de agroquimicos, el dueño de la plantación es quien hace las mezclas de los insumos utilizados.

Figura 5.

Aplicación de fertilizante granulado en una plantación de maíz.

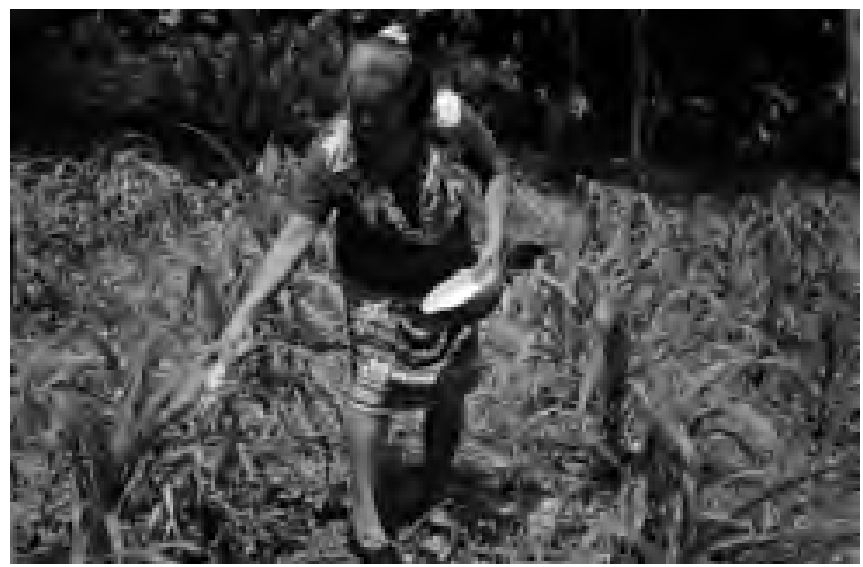

Habitualmente la mujer es la encargada de aplicar el fertilizante granulado, pues al ser considerado una sustancia menos tóxica y peligrosa, ellas pueden manipularlo.

espalda o maquinaria de riego especializada las que se utilicen para aplicar este tipo de sustancias. En ambos casos, como medidas de protección personal consideran suficiente el uso de botas, manga larga, y un pañuelo para cubrir nariz y boca, cuando el químico es considerado de alta toxicidad.

La experiencia previa de intoxicación no es una causa para modificar dicho comportamiento, o bien para recurrir a mínimas medidas de cuidado personal. Liquido, quien se ha intoxicado en dos ocasiones, 
comenta que él está acostumbrado a aplicar los químicos de la siguiente manera: "Yo riego el líquido nada más con botas, porque yo no me pongo como lo aplica la dosis, que dice que hay que usar manga larga, mascarilla, yo lo riego nada más que con botas".

Quemante recuerda que durante el tiempo que trabajó como peón agrícola, ni él ni los otros compañeros se protegían: "Yo trabajé en una finca por 17 años y regamos herbicida pero no andábamos con nada de protección". Esta experiencia se reproduce en el relato de Fuerte y Necesario. El primero comenta: "Yo voy así no más, si uno mira el daño, le hace daño”. Necesario asegura que él tampoco toma ninguna previsión, "Cuando aplicamos no uso nada de eso, ni botas, ni guantes".

La decisión de no utilizar equipo para protegerse del contacto directo se asocia con la percepción de vulnerabilidad o superioridad física. Por ejemplo, Necesario se muestra escéptico al riesgo, según piensa, son otros quienes corren mayor riesgo de enfermar, pues en su caso particular, aunque se ha intoxicado en tres ocasiones: "El agroquímico no me hace daño". Fuerte nunca se ha intoxicado, a su parecer depende de "la defensa que se tenga, cómo esté uno de salud, a una persona muy débil le puede afectar".

$\mathrm{Su}$ hermano, por el contrario, habiendo sido víctima de intoxicación aguda por exposición, reflexiona en cómo el agricultor evade la peligrosidad a la que se expone. Según recuerda, él advertía a sus compañeros de la finca donde trabajaba: "Uno de ellos se puso a aplicar un líquido para unos mangos, yo le decía tenga cuidado. Cuando lo veo sentado, al hospital fue a parar, y ahora ni un detergente puede tocar".

Estos niveles de incidencia del agroquímico en el cuerpo humano y la relación salud enfermedad son planteados por los cinco agricultores entrevistados a partir de sus experiencias de intoxicación, sus efectos crónicos y agudos se estudian a continuación.

\section{"Me sentí mal”; intoxicados por exposición laboral}

Fuerte, Liquido y Quemante conocen bien los efectos y las molestias de una intoxicación por agroquímicos. Aspirarlo y palparlo de forma directa ha provocado en ellos distintas reacciones, algunas veces la piel se ha irritado o quemado, en otras ocasiones se ha experimentado un desvanecimiento del cuerpo y, en otros casos, una reacción alérgica similar a un episodio asmático.

Un solo evento de intoxicación fue suficiente para que Quemante generara una reacción alérgica respiratoria y dérmica. Su historia de vida está marcada por aquella primera vez que un herbicida le quemó la espalda; tenía aproximadamente 30 años de edad y trabajaba como peón agrícola. Con una expresión reflexiva en el rostro, relata cómo fue que se intoxicó: "Me comenzó en la espalda, me comenzó quemando, y decía el patrón, eso no quema. Se me hizo la rodaja y ahora yo me pongo una bomba en la espalda y siento que tengo ese estorbo ahi”.

Cuando tenía como 20 años de edad, trabajando para una compañía bananera, Líquido afirma que por 4 años aplicó "químicos bravos para la salud de uno, como el Nemagón”. Al recordar la última vez que se intoxicó medita: "Con el Gramoxone me intoxiqué, yo me bañe de inmediato, pero me sentí mareado, al extremo que no me podía ni parar. Yo no usaba guantes ni mascarilla, ni nada de eso". Aunque en más de una ocasión su cuerpo ha experimentado reacciones ante el contacto con el agroquímico, ya que ha sentido picazón en la piel, dolor de cabeza o malestar de estómago después de su aplicación, Necesario recuerda tres momentos significativos en su vida. La primera vez que el agroquímico lo hizo sentir mal ocurrió cuando era un adolescente: "Una vez estando carajillo, me buscó un señor para que fuera a fumigarle herbicida, me puse rojitito la cara y todo eso, yo tenía como 15 años".

Tiempo después, siendo ya un hombre adulto de aproximadamente 35 años de edad, Necesario fue nuevamente víctima de intoxicación. En esta ocasión la sustancia involucrada fue la Cipermetrina que cargaba en una bomba de espalda: "El químico se regaba, yo seguí, pero en la tarde sentía mucho sarpullido, me bañe muchas veces y nada, esa noche no logré dormir".

La última vez ocurrió hace como diez años y en esta ocasión su hijo mayor también resultó intoxicado, ambos aplicaban el mismo agroquímico, tuvieron las mismas reacciones, pero Necesario enfoca la atención en la condición que presentó su hijo, dirigiendo la mirada al muchacho, comenta: "La bomba chorreó el líquido, le dio vómito, mareo, dolor de cabeza, estuvo en el hospital".

Las formas más comunes de tratar estos episodios de intoxicación son mediante la preparación de remedios caseros, como consumir leche o limón con sal, así como bañarse varias veces. Necesario y Quemante coinciden en los aportes de la leche para contrarrestar los efectos de la intoxicación. Al recordar la forma en cómo se sobrepuso a su primer episodio de intoxicación, Necesario comenta: "Me dieron leche nada más”; estrategia que también aconseja Quemante: "Nada más que si se tiene alguna cosa, se toma un poquillo de leche o limón ácido".

Cuando dichos remedios no surten efecto es cuando se hace la decisión de acudir al centro médico. Así procedió Líquido la última vez que se intoxicó, al no sentir mejorías con estos medicamentos caseros, y percibiéndose cada vez peor, recuerda que fue su esposa la que le indicó la importancia de ser atendido por un médico: "Esta me dijo, "tienen que verlo, vamos al hospital".

Haber sufrido los efectos directos de la intoxicación cambia la percepción del riesgo y la concepción del agroquímico, sobre todo cuando pasa el tiempo y la persona continúa con malestares físicos. Además existe una relación entre edad y concientización de cómo el agroquímico enferma. Líquido y Quemante, los más adultos de este grupo de agricultores, quienes se quejan de dolores reumáticos y experimentan reacciones al respirarlo y tocarlo, son los únicos que consideran que a largo plazo la exposición a estas sustancias enferma y provoca malestares crónicos.

En su caso, Liquido expresa, mientras señala sus rodillas y brazos: "Esto lo adquirí por los líquidos que uno riega, lo tullido que estoy de los huesos, las rodillas, los brazos, vieras que no aguanto, tengo como quince años de estar padeciendo". Quemante se queja de las consecuencias de aquel herbicida que se derramó en su espalda: "En veces como que se me duerme, me busca doler, me muerde, pero no hay nada de cicatriz".

Por el contrario, para Necesario, Peligroso y Fuerte sufrir los efectos de la intoxicación es muestra de debilidad masculina, y una consecuencia directa del trabajo agrícola. Ellos interpretan las alteraciones a la salud por intoxicación como una situación común de la exposición al químico. Estos relatos de vida evidencian como un simple síntoma, la vulnerabilidad de un cuerpo enfermo, y en peor medida, las continuas dolencias físicas son ejemplos contundentes de que el agroquímico enferma al ser humano.

Pero, ¿cuáles son las relaciones que se establecen con el químico en el espacio de convivencia cotidiana? Estas relaciones se estudian en el siguiente apartado.

\section{Conviviendo cerca del agroquímico; escenarios de riesgo humano y ambiental}

La exposición humana, animal y ambiental en el entorno doméstico se relaciona con la cercanía existente entre el espacio de 
cultivo, el sitio de almacenaje del agroquímico, y la ubicación de la vivienda. En los cinco casos estudiados la casa de habitación se encuentra dentro del mismo terreno donde se cultiva, situación que facilita la exposición de la familia cuando se aplican insumos químicos.

Los agricultores son conscientes de la importancia de mantener y guardar los agroquímicos fuera de la casa de habitación, ya que a su parecer podría ser peligroso para la salud conservarlos dentro de la vivienda. Para ello cuentan con una bodega, una galera, o bien se ha dispuesto un sitio al aire libre donde resguardarlos; estos son espacios considerados por los entrevistados como sitios seguros.

No obstante, es poca la distancia que existe entre un sitio y otro; la mayor distancia entre vivienda y bodega es de $30 \mathrm{~m}$, siendo la menor de tan sólo $8 \mathrm{~m}$. El riesgo a la exposición se incrementa debido a las conductas asumidas en el almacenamiento del agroquímico. Ningún jefe de hogar guarda sus insumos químicos bajo llave, se practica habitualmente el reenvasado, y en ocasiones se suele colocar el agroquímico en el suelo en envases no etiquetados. En cuanto a la exposición animal, en todos los hogares el sitio de almacenaje se localiza al lado del espacio donde descansan o transitan cotidianamente animales domésticos. En relación a los niveles de exposición ambiental el mayor riesgo que se observa es la presencia de pozos de agua y ríos ubicados cerca del sitio de almacenaje, y de los terrenos de cultivo.

Figura 6.

Espacio de convivencia de la familia de Líquido.

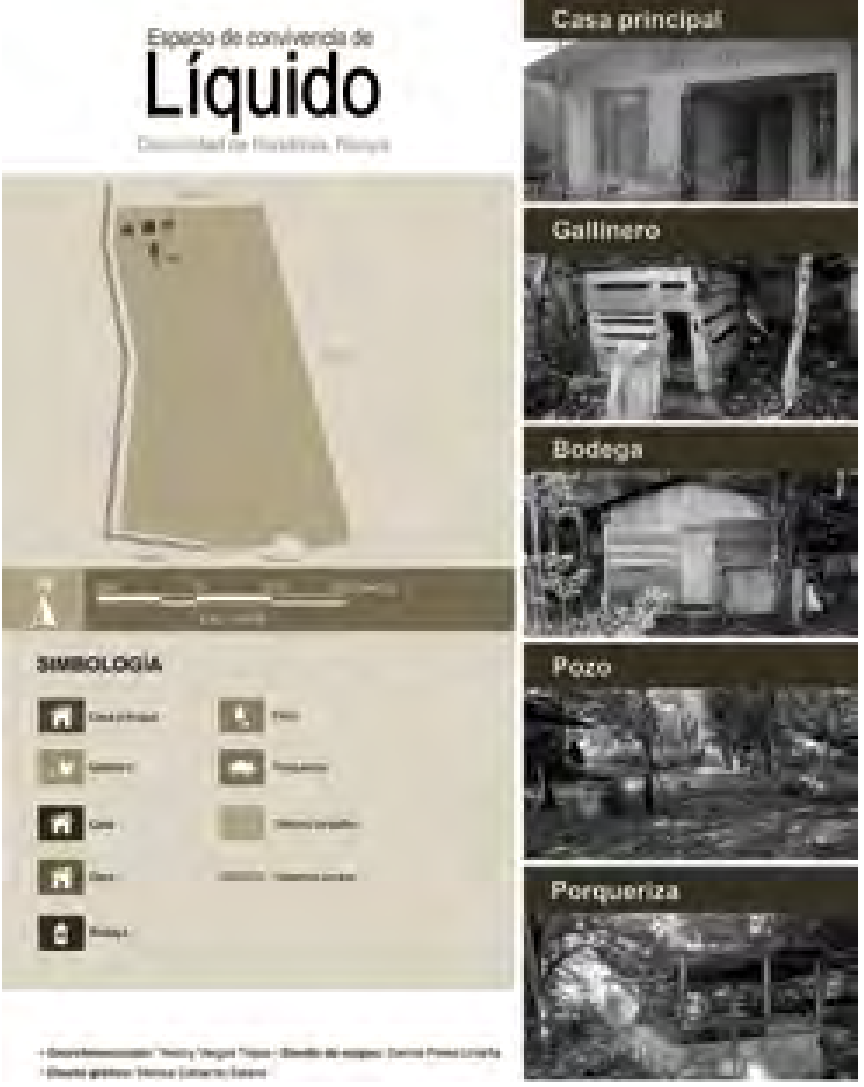

Líquido actualmente destina una hectárea o menos a la siembra del maíz, según indica prefiere alquilar y pedir pago en especie con elotes, chilotes y semilla, ya que su estado de salud y edad no le permite cultivar como lo hacía cuando era más joven.
Figura 7.

Espacio de convivencia de la familia de Fuerte.
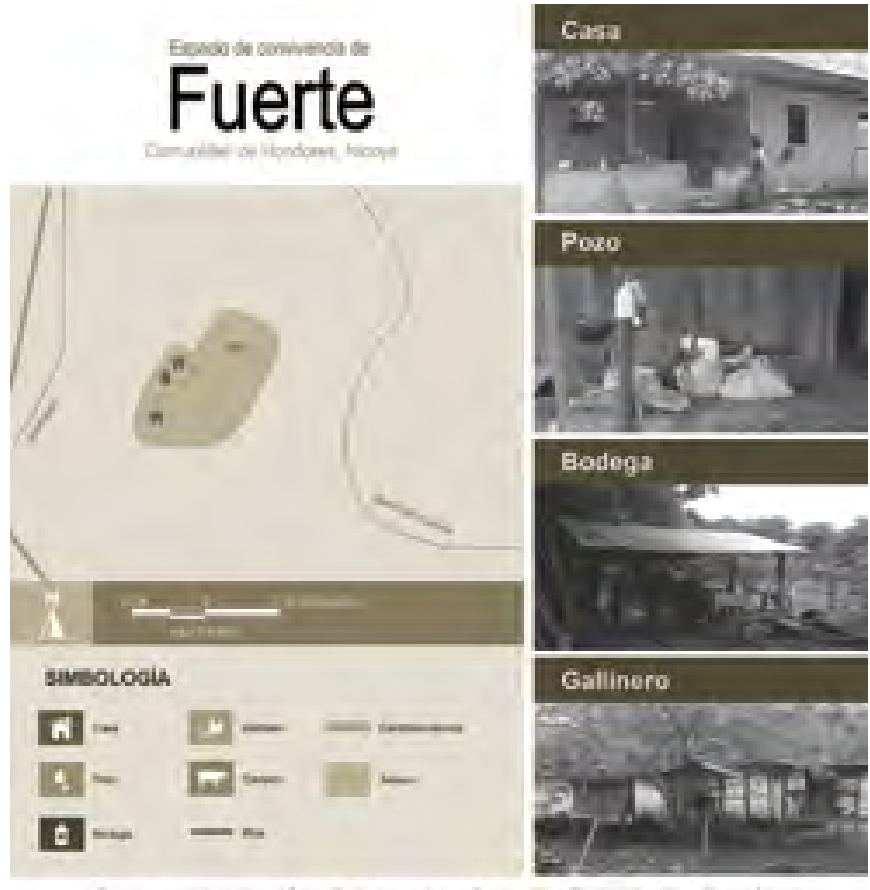

En su parcela Fuerte tiene ocho años de haber sembrado pasto de la especie brachiaria, introdujo esta especie porque en su opinión, "el jaragua no ha querido funcionar mucho, porque las tierras ya no dan sin abono y el abono está muy caro".

A continuación se estudian las distintas maneras en que las familias agricultoras conviven espacial y cotidianamente con el químico. Las relaciones de cercanía se representan mediante la georreferenciación de la vivienda, la bodega de almacenaje, el sitio de cultivo, y la zona de descanso de animales como gallinas, ganado y cerdos.

\section{Líquido}

Como se observa en la Figura No 6 el sitio donde se ubica la bodega de almacenaje también es compartido por el gallinero, la porqueriza y un pozo de agua en desuso, del cual se abasteció la familia por cerca de 17 años antes de contar con cañería. Líquido suele asegurar el acceso a la bodega manteniendo la puerta cerrada con mecate. En su interior almacena, en barriles de acero, semillas criollas para el cultivo. El químico lo mantiene en el suelo en envases etiquetados y en algunos casos este ha sido re-envasado. Para Líquido las relaciones de cercanía con el agroquímico no constituyen un factor de riesgo para la familia; sin embargo, él y su esposa opinan que su actual estado de salud, así como la muerte de su hijo mayor a los veintitrés años de edad a causa de un cáncer desarrollado en la infancia, sí se debe a la exposición al agroquímico, y principalmente al consumo de alimentos contaminados por este. Al respecto, indica: "Nuestro hijo padeció de ganglios cancerosos porque comía la tortilla de maíz envenenada".

\section{Fuerte}

Como se aprecia en la Figura No 7, su casa de habitación se encuentra rodeada de pequeños gallineros y un área de pastos, en el sitio se ubica la vivienda de uno de los hijos. La familia cuenta con un pozo de agua ubicado en las afueras de la vivienda del cual obtienen el recurso hídrico que consumen, aunque desconocen su potabilidad. 
Figura 8.

Espacio de convivencia de la familia de Quemante.

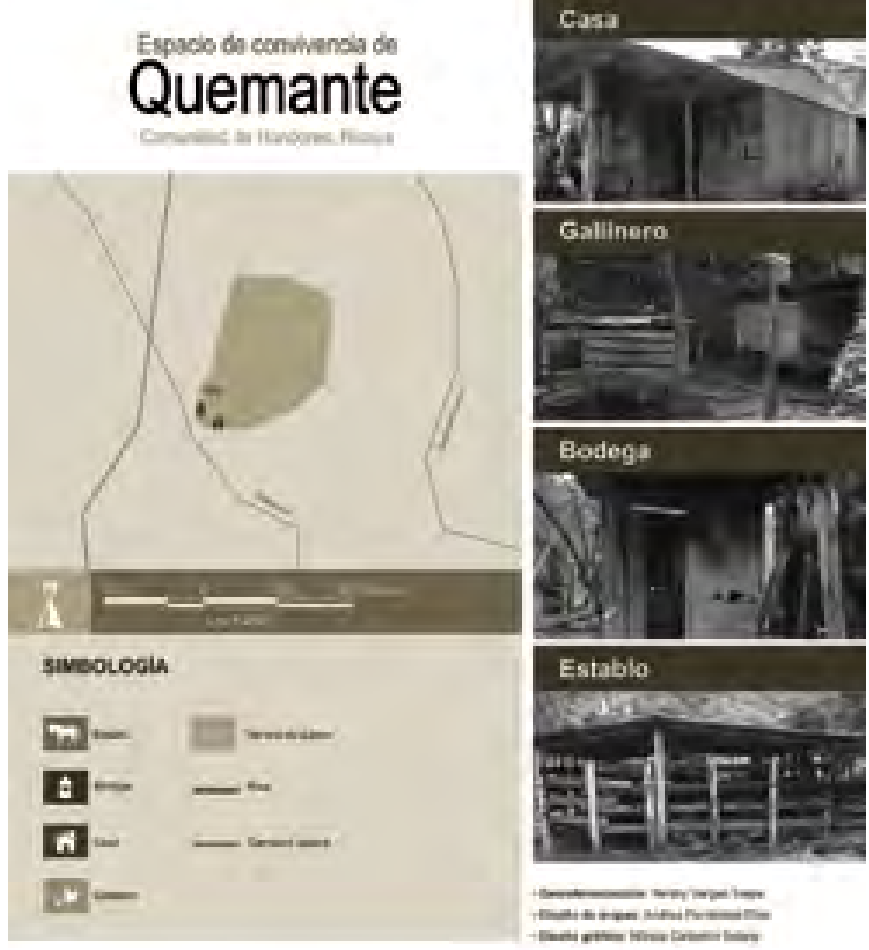

Quemante siembra maíz blanco y amarillo, y cuando logra una buena cosecha saca aproximadamente 35 sacos de elotes.

Este agricultor dispone sus insumos químicos en la misma galera donde su esposa suele preparar alimentos. El agroquímico se coloca en el suelo, al lado de la leña que se utiliza para cocinar. En el sitio, cerca y sobre las bombas de atomizar, duermen gallinas y perros, también habitualmente juegan sus nietos. En los alrededores del lugar se observan espacios destinados a la quema de residuos sólidos domésticos y de agroquímicos.

\section{Quemante}

Quemante improvisó un baño en desuso para almacenar el agroquímico, por los alrededores del almacenaje juegan nietos, transitan en busca de alimento gallinas, perros y gatos, y también descansa el ganado. En la Figura No 8 se aprecia que la casa de habitación se encuentra frente al sitio de almacenaje donde se dispone el agroquímico, colgado a la pared en una bolsa plástica. En los alrededores de su vivienda se han dispuesto distintos sitios para quemar y enterrar los desechos sólidos domésticos, así como envases de agroquímicos. A pesar de que el olor del agroquímico le provoca alergia dérmica y respiratoria, Quemante considera que no existe riesgo para su salud: "Porque los insumos que utilizo son livianos"; mientras señala un envase, indica: "Son de etiqueta amarilla".

\section{Necesario}

Como se aprecia en la Figura No 9 en los alrededores de la vivienda se localiza la bodega de almacenaje y maquinaria de riego. El sitio de disposición de los agroquímicos consiste en un galerón abierto sin puerta ni ventajas, ubicado al lado del gallinero. El pozo de agua del cual se abastece la familia se ubica a menos de $100 \mathrm{~m}$ de la casa de habitación, en ese mismo terreno se cultiva maíz y frijol, y en ocasiones se preparan las mezclas de los agroquímicos.
Figura 9.

Espacio de convivencia de la familia de Necesario.

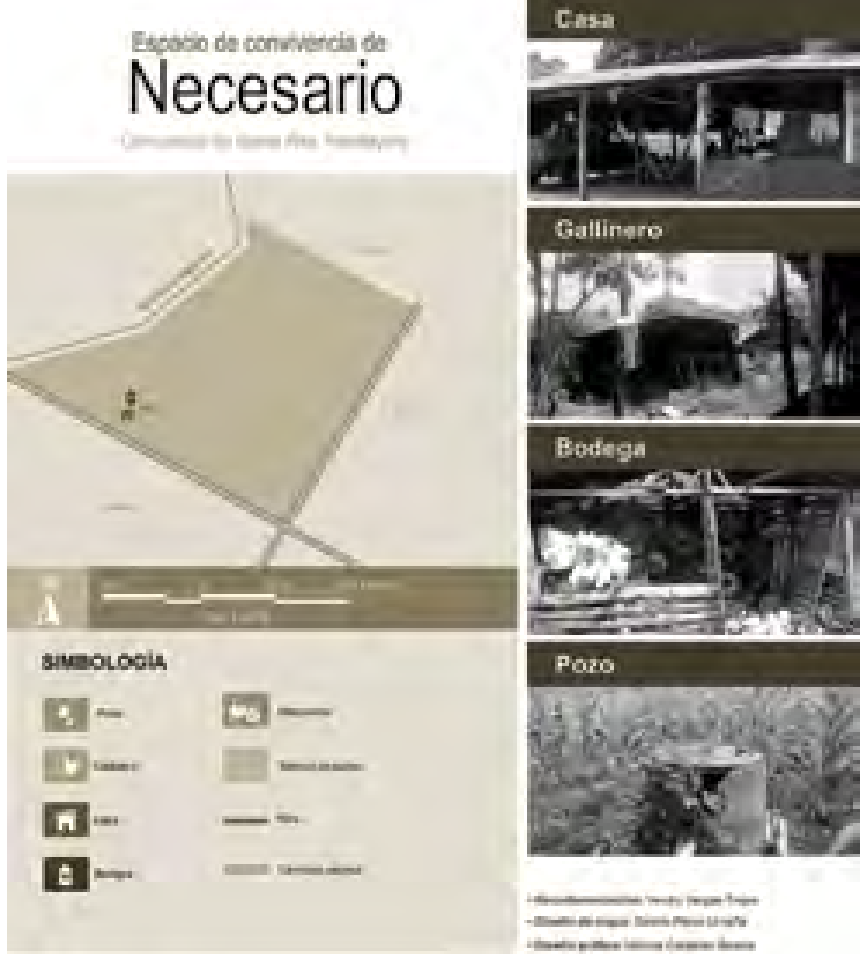

En el año 2006, Necesario sembró por primera vez 5 has de sandía logrando una cosecha de aproximadamente 250.000 kilos.

Necesario se queja de un dolor constante en una de sus rodillas, conoce los efectos de la intoxicación por agroquímicos, y sabe distinguir con facilidad la toxicidad de cada uno de ellos. Sin embargo, él y su familia manipulan los insumos químicos sin temor a sus efectos futuros. Necesario considera que su trabajo es lo que le "llena de vida y salud".

\section{Peligroso}

La Figura No 10 muestra el espacio de convivencia de Peligroso con el agroquímico, el cual está determinado por la distancia de una pared entre su casa de habitación y la galera de almacenaje. En la misma galera conviven gallinas, perros y gatos, y se ubica el pozo de agua. En sus afueras se suelen depositar y quemar los residuos de envases de agroquímicos.

A pesar de que suele cotidianamente quemar residuos de agroquímicos cerca de este, y almacenar dichos insumos en la misma galera, Peligroso opina que existe poca probabilidad de contaminación del recurso hídrico.

\section{DISCUSIÓN}

Los agricultores de Hondores y Santa Rita son vulnerables a efectos en su salud debido al tipo de exposición ocupacional y ambiental con la que interactúan diariamente. Los factores de riesgo se concentran en las actividades laborales que desarrollan en el manejo directo de los agroquímicos y las prácticas sanitarias de su mezcla y aplicación. En tanto, el riesgo ambiental está asociado con el almacenaje y la convivencia permanente en el espacio de cultivo donde además están expuestos el recurso hídrico y los animales. 
Figura 10.

Espacio de convivencia de la familia de Peligroso.

\section{Peligroso}

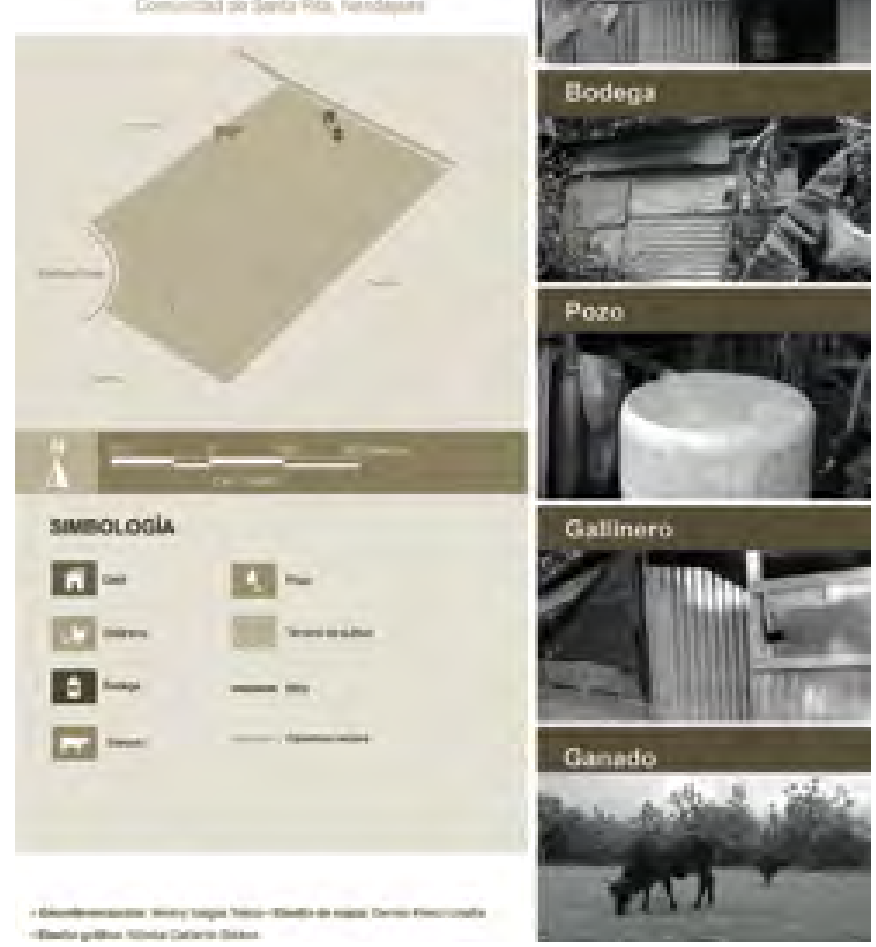

En promedio anualmente Peligroso destina una extensión de tres hectáreas para el cultivo de maní logrando una cosecha cercana a los 300 quintales. Además destina una extensión de 1,2 has para el cultivo de mango.

A pesar de que suelen reconocer a los agroquímicos que utilizan por su nombre y sus efectos sobre cultivos y naturaleza, sólo se percibe el peligro de estas sustancias para la salud humana cuando se han experimentado los efectos crónicos de su exposición. Sin embargo, el hecho de suponer que no existe peligro ante la exposición a dichas sustancias tóxicas, no implica que sus efectos negativos estén siendo evitados y controlados por estos trabajadores agrícolas y sus familias.

Por tanto, es preciso considerar, ¿de qué manera la exposición cotidiana al agroquímico supone una negación de su riesgo?, o bien, ¿cómo la familia logra convivir con el peligro e invisibilizar sus efectos humanos y ambientales? Estos escenarios de exposición, convivencia y negación serán analizados en los siguientes apartados.

\section{Exposición y negación del riesgo}

En la cotidianidad del trabajo agrícola los jefes de hogar entrevistados experimentan la exposición directa con el agroquímico. La decisión de no utilizar equipo de protección para realizar las mezclas, aplicar el insumo y limpiar el equipo es habitual entre los agricultores de ambas comunidades.

Como medidas de protección personal se dice utilizar botas, manga larga, y un pañuelo para nariz y boca, pero en la práctica cotidiana las botas son la única prenda que usan, decisión en la que además influyen las altas temperaturas de la región guanacasteca, y el imaginario de que hay que ducharse hasta después de enfriarse porque "los poros se abren". La experiencia previa de intoxicación no es una causa para modificar dicho comportamiento, o para recurrir a otras medidas de cuidado personal.

Estudios realizados entre agricultores costarricenses productores de tomate y chile en provincias como Alajuela, Cartago, Heredia, Guanacaste y San José determinaron que estos no utilizan el equipo completo de protección aduciendo alto costo e incomodidad. Actitudes como la ignorancia, la imprudencia y el machismo, contribuian a que algunos consideraran como inocuos varios de los productos aplicados por lo que no temían intoxicarse. ${ }^{29}$ Las mismas percepciones se observan en el presente estudio cuando se indica que los químicos de etiqueta amarilla "son livianos, no hacen daño", mientras la etiqueta roja "va directo a matar".

No obstante, haber sufrido los efectos directos de la intoxicación cambia de alguna forma la percepción del riesgo y la concepción del químico. Por ejemplo, ante los efectos de la intoxicación aguda, al menos dos de los agricultores concluyen que hay agroquímicos "bravos" y "peligrosos" a los que hay que "tenerles miedo". Tal y como opinan agricultores expuestos a plaguicidas en el Estado de Río de Janeiro, existe riesgo sólo donde se hace evidente, es decir, cuando se experimentan los efectos físicos de la exposición. ${ }^{26}$

Sin embargo, en estas prácticas quimizadas de cultivo el agroquímico no enferma o afecta por igual a todos. En el caso de los tres agricultores más jóvenes se sugiere que sufrir los efectos de la intoxicación aguda, además de ser una muestra de debilidad masculina, es una consecuencia directa del trabajo agrícola, y por tanto un acontecimiento habitual que puede ocurrir en cualquier momento.

Una reacción similar es externada por agricultores mexicanos, quienes aun cuando conocen el peligro de intoxicación, su percepción del riesgo se modifica debido al contacto cotidiano en la manipulación y el almacenaje del agroquímico, pues ellos no perciben que están expuestos a sustancias peligrosas para su salud. ${ }^{30}$

Por el contrario, para los dos agricultores más adultos, quienes ya no logran realizar la misma actividad física, se quejan de dolores reumáticos, y sienten que el químico continúa quemando su cuerpo, o experimentan reacciones al respirarlo y tocarlo, efectivamente a largo plazo la exposición a estas sustancias enferma y provoca efectos crónicos. Esta es la misma respuesta que se identifica entre trabajadores de los valles agrícolas de Mexicali y San Quintín en México, donde sólo los agricultores más adultos perciben y padecen las enfermedades crónico-degenerativas asociadas con la exposición a plaguicidas. ${ }^{31}$

Otra forma de interpretar que los agroquímicos pueden afectar a unos y no a otros, es valorando el grado de toxicidad de la sustancia manipulada; al respecto se hace explícita la diferencia entre plaguicidas y fertilizantes. La intuición masculina sugiere que mujeres y niños no deben exponerse a venenos como los plaguicidas, no obstante se percibe al fertilizante como una sustancia menos tóxica, la cual puede ser manipulada por esposas e hijas, quienes de hecho son las encargadas de aplicarlo sin necesidad de utilizar guantes $u$ otros equipos de protección personal. Al permitirse que los más vulnerables de la familia manipulen este tipo de sustancias es probable que se esté asumiendo una posición semejante a la observada entre agricultores en los Altos de Morelos (México), entre quienes predomina la idea de que si el producto que se aplica tiene la finalidad de eliminar plagas de insectos es "veneno", en tanto cualquier otro agroquímico no lo es y por lo mismo, no resulta dañino. ${ }^{32}$ Estas opiniones son contrastantes con 
las emitidas por los indígenas del Altiplano Maya en Guatemala, para quienes los fertilizantes "tienen enfermedad", pues no sólo han afectado la tierra, sino la salud de las personas que ahora son más proclives a enfermar. ${ }^{33}$

En otras palabras, es importante considerar que aunque los fertilizantes no tienen las características de toxicidad que tienen los plaguicidas, tampoco están exentos de impactos en la salud y el ambiente. ${ }^{9} \mathrm{Al}$ menos en Costa Rica investigaciones realizadas durante la última década han detectado la presencia de nitratos, tanto en aguas superficiales, como en aguas subterráneas. ${ }^{34,35}$

Con respecto al impacto de estas sustancias en el suelo, también se identifica en las narraciones de los cinco agricultores interpretaciones significativas, pues han observado efectos negativos en la tierra de cultivo, ya que no es posible hacer producir un suelo cansado sin su ayuda, de forma concreta uno de ellos indica, "el terreno ya no produce sin el alimento químico, los fertilizantes se han hecho necesarios, nos han hecho dependientes".

\section{Relaciones del peligro cotidiano}

En el espacio doméstico personas, animales y pozos de agua conviven e interactúan cotidianamente en el mismo sitio donde se almacena el agroquímico, se queman sus residuos o se hacen sus mezclas y aplicaciones. La tarea de almacenarlo fuera de la vivienda se interpreta como una forma adecuada de evitar riesgos de exposición. Pero no se advierte el peligro de colocarlo en el suelo, no etiquetarlo o mantener la bomba de atomizar en el área donde se alimentan y descansan los animales, o en peor medida, dentro de la misma vivienda.

Estas costumbres son comunes entre familias agricultoras de la región de Guanacaste, donde ya otros estudios habian identificado que una práctica usual entre trabajadores agrícolas guanacastecos consistía en almacenar plaguicidas en los cuartos de las casas, utilizar el reenvasado, y colgar los envases en un árbol, sin percibir o considerar los efectos humanos y ambientales de tales prácticas. $^{36}$

Otra costumbre habitual entre agricultores de la región es residir de manera permanente en el campo de cultivo, desde los años ochenta se había identificado la presencia de viviendas familiares dentro de las áreas de cultivo, cuyos moradores permanecían en estrecho contacto con los plaguicidas durante los periodos de aplicación. ${ }^{37}$ Estas conductas también han sido observadas entre trabajadores agrícolas mexicanos ${ }^{20}$ e indígenas en el Altiplano Maya guatemalteco. ${ }^{23}$

En el caso de los indígenas mayas se ha identificado que al localizarse los terrenos de cultivo cerca de hogares y suministros de agua, una vez aplicados los agroquímicos, estos se esparcen fácilmente y pueden contaminar la comida y el recurso hídrico que ingiere la población. En el caso que nos ocupa, es probable que haya riesgo de contaminación humana y ambiental en los niveles que indican estos estudios, de hecho una de las familias supone que existe algún tipo de encadenamiento entre la aplicación de agroquímicos, consumo de alimentos contaminados y efectos en la salud.

No obstante, resulta particular que ninguna de las familias exprese preocupación o temor por residir de manera permanente en la zona agrícola, y verse de alguna forma expuestas a las actividades de fumigación y fertilización, debido a la cercanía entre vivienda y espacio de cultivo. Tampoco consideran que exista riesgo de exposición por ingresar a campos fumigados recientemente, pues a su parecer, el agroquímico penetra de forma inmediata el suelo.

Estos imaginarios son cuestionados por investigaciones realizadas con trabajadores agrícolas colombianos en las cuales se asegura que el riesgo de intoxicación es latente cuando se está cerca de espacios que han sido fumigados. Pues se ha logrado determinar que una de las causas de su intoxicación es la exposición indirecta al encontrarse en los alrededores de las áreas donde se aplican plaguicidas. ${ }^{13}$

\section{Limitantes por fortalecer; un reto multidisciplinario}

A pesar de los supuestos que el presente estudio permite hacer, es claro que como primer acercamiento a la comprensión de la problemática se dificulta generar evidencias concretas de los impactos humanos y ambientales que se sugieren o interpretan. Se requiere complementar con estudios químicos y epidemiológicos que faciliten, desde una visión multidisciplinaria, interpretar las incidencias humanas y ambientales de la agricultura quimizada. De alli que se ameriten análisis de laboratorio para determinar la presencia de residuos de agroquímicos en tierra, agua, organismos vegetales y animales. Así como estudios clínicos para determinar presencia de plaguicidas en sangre y orina en los jefes de hogar y en el conjunto de su familia, de forma que se puedan complementar y contrarrestar los escenarios de riesgo identificados y las conductas a ellos asociadas.

\section{Recomendaciones futuras; los humedales artificiales son una opción}

Los sistemas de cultivo orgánico se perfilan hoy como una necesidad; es preciso transitar de una agricultura quimizada hacia una más sustentable, sin impactos perjudiciales para la salud humana y el ambiente. En la cotidianidad de su trabajo agrícola los cinco agricultores entrevistados consideran la agricultura orgánica como una opción, los abonos orgánicos se categorizan como "buenos y necesarios”, pero ello no significa que estén llevando a la práctica una agricultura más ecológica.

En tal sentido, una manera de incentivar a pequeña escala la agricultura orgánica, promoviendo escenarios experimentales para la siembra de hortalizas hidropónicas, consiste en habilitar en sus parcelas la instalación de humedales artificiales, también llamados biojardineras. De esta manera las familias pueden limpiar las aguas grises producidas en el hogar y conducirlas desde sus viviendas al sistema; las aguas que salen de este se podrán reutilizar en el riesgo de los cultivos y en el diseño de pequeñas huertas hidropónicas.

Esta tecnología ha sido desarrollada en Costa Rica bajo el concepto de ecosaneamiento, y su implementación en el país es reciente; no obstante, ha resultado bastante atractiva para las familias costarricenses, principalmente por su bajo costo y sencilla operación. ${ }^{38}$ Como prueba piloto en el año 2014 se construyó una biojardinera en la parcela de Necesario, sus condiciones eran idóneas, una familia de siete miembros con un alto consumo de agua, que además depende del agua de pozo para satisfacer sus necesidades domésticas y demandas agrícolas.

Tres acciones se emprenderán en este 2015 para la construcción de una huerta familiar hidropónica en este hogar: estudios de aguas en las salidas del sistema que permitan verificar su calidad para ser reutilizada en el riego de cultivos, asesoria a la familia en agricultura hidropónica, y construcción de la huerta.

El reto de contribuir con la seguridad alimentaria y nutricional a través de este tipo de sistemas, impulsando huertas familiares, módulos de educación agropecuaria, y sensibilización en el cuidado de la salud humana y ambiental, evidentemente motiva el desarrollo de otros procesos de investigación y extensión comunitaria en la cuenca hidrográfica Morote, donde el compromiso del agricultor y su familia son indispensables. 


\section{Agradecimientos}

Esta primera fase investigativa ha sido posible gracias al apoyo brindado por la Universidad Nacional de Costa Rica a través del programa Horizontes Ambientales: Innovación y Cambio; y del proyecto "Acción socioambiental participativa para la gestión inte- gral de la cuenca hidrográfica del río Morote" ejecutado en el periodo 2012-2014. El agradecimiento es extensivo a los cinco agricultores y sus familias que facilitaron un espacio de diálogo y amistad para conocer y aprender de sus experiencias, necesidades $\mathrm{y}$ retos en el arduo trabajo de hacer producir la tierra.

\section{ANEXO 1.}

\section{DATOS DEMOGRÁFICOS DE LA PERSONA ENTREVISTADA}

\begin{tabular}{|l|l|l|l|}
\hline Fecha aplicación: & $\begin{array}{l}\text { Teléfono persona } \\
\text { entrevistada: }\end{array}$ & $\begin{array}{l}\text { Dirección casa } \\
\text { de habitación }\end{array}$ & $\begin{array}{l}\text { Dirección sitio } \\
\text { de trabajo }\end{array}$ \\
\hline
\end{tabular}

\section{Nombre:}

2. ¿Cuál es su edad en años cumplidos?

3. ¿Cuál es su estado civil?

4. ¿Tiene hijos?

5. Actualmente, ¿cuál es su ocupación?

6. ¿Cuál es su último año de educación aprobado?
1. Ninguna
2. Primaria incompleta
3. Primaria completa
3. Secundaria incompleta
4. Secundaria completa
5. Universitaria incompleta
6. Para universitaria completa
8. Universitaria completa
7. Universitaria completa
9. Posgrado universitario completo
(Bachiller o licenciatura)
10. NS/NR

\section{ACTIVIDADES DE PRODUCCIÓN AGRICOLA DESARROLLADAS EN LA ZONA DE ESTUDIO}

1. ¿Cuáles son las actividades agricolas que actualmente se desarrollan en Nicoya, Nandayure?

2. Antes del desarrollo de estas actividades agricolas, recuerda usted, ¿qué otros productos se cultivaban en la zona?

3. Aproximadamente, ¿en qué años (décadas) se cultivaban los productos agricolas que indica?

4. En sus recuerdos de infancia, ¿qué tipo de productos agricolas recuerda usted que se cultivaban acá en la zona de Nicoya-Nandayure?

5. Actualmente, ¿a qué tipo de actividades agricolas se dedica usted?

6. Por casualidad, ¿algún otro miembro de su familia (abuelo, padre, hermanos, tíos) se dedicó, antes que usted, a este tipo de actividades agricolas?

7. ¿Usted cuenta con su propio terreno para la siembra de estos productos?

8. ¿Cuál es el destino principal de sus productos agrícolas? (Autoconsumo, mercado local, nacional).

\section{USO DE INSUMOS QUIMIICOS EN LAS ACTIVIDADES AGRICOLAS: SUS APORTESY} DESVENTAJAS

9. ¿Qué técnicas (prácticas) ha probado para mejorar su producción agrícola?

10.¿Qué piensa usted con respecto al uso de abonos y plaguicidas para mejorar su producción agrícola?

11. Recuerda usted: ¿a partir de qué momento (año-década) los agricultores de esta zona (Nicoya-Nandayure) empezaron a utilizar abonos y plaguicidas para mejorar su producción agrícola?

12.Siendo usted un niño, ¿en alguna ocasión escuchó que los agricultores de esta zona utilizaran abonos y plaguicidas en sus actividades agricolas?

13.¿Cuáles son los abonos y plaguicidas que utiliza con mayor frecuencia?

14.En aquellos años, cuando se empezaron a utilizar los abonos y los plaguicidas en la producción agrícola, ¿qué recuerdos tiene usted en relación a los beneficios que, se decia, traía el uso de estos insumos químicos para la agricultura?

15. ¿Qué beneficios, considera usted, aportan los abonos y los plaguicidas a sus cultivos? 16.A su parecer, ¿qué desventajas tiene el uso de los abonos y los plaguicidas?

\section{PERCEPCIÓN DEL RIESGO EN RELACIÓN AL USO DE ABONOS Y PLAGUICIDAS}

17. Cuando usted aplica esos abonos y plaguicidas, a nivel personal, ¿qué cuidados tiene?: qué hace antes, durante y después de aplicarlos.

18.¿Cómo almacena usted los insumos quimicos? ¿Qué medidas de seguridad considera que son importantes tomar en cuenta a la hora de almacenar estas sustancias?

19. ¿En alguna ocasión ha tenido accidentes (intoxicación) usted, o algunos de sus familiares o compañeros de trabajo al aplicar abonos y plaguicidas?

20.En su opinión, ¿qué conocimientos debe tener una persona cuando hace las mezclas, y aplica y manipula los abonos y plaguicidas?

21. A su parecer, ¿es posible que una persona que utilice abonos y plaguicidas en sus actividades agricolas, pueda enfermarse?

22. ¿Usted considera que el uso de abonos y plaguicidas puede contaminar de alguna forma el ambiente? 
ANEXO 2. Guía de observación.

\section{CONDICIONES DE ALMACENAJE DEL AGROQUIMICO}

Cantón:

Distrito:

Comunidad:

Nombre del agricultor:

Fecha de aplicación:

\section{CARACTERISTICAS DE LAS BODEGAS}

1.1. UBICACIÓN:

1. ¿La bodega se ubica cerca de?:

Espacios

1. Cursos de agua, río, pozos, otras fuentes de suministro de agua para uso doméstico o para animales.

2. Casas de habitación.

3. Zonas de descanso o espacios recreativos.

4. Corrales, establos o gallineros.

5. Pilas, lavatorios, duchas o tubos con acceso a agua potable.

1.2. CARACTERISTICAS DE CONSTRUCCIÓN:

2. ¿La estructura física de la bodega presenta?:

\section{Materiales, medidas de seguridad y señalización}

1. Paredes interiores con grietas.
2. Techo de estructura metálica u otros materiales ligeros (fibra de vidrio).

3. Puertas metálicas

4. Puertas con candados.

5. Iluminación natural o eléctrica.

6. Señalización según tipo de peligro (tóxico, inflamable, otras).

7. Señalización según tipo de almacenamiento (plaguicidas, abonos, otros).

8. Tipo de material de las paredes:
8.1. Madera
8.2. Concreto
8.3. Madera y concreto.
8.4. Otro material: especificar.

3. ¿La bodega cuenta con medidas de seguridad 1. Botiquín médico. y atención de emergencias como?:

2. Escrito en las paredes o en algún otro sitio números de emergencia, 911, clínicas cercanas, nombre de médicos, otros.

4. ¿En los alrededores de la bodega se observan sitios donde se quemen los residuos domésticos?

II. DISPOSICIÓN Y ROTULACIÓN DEL PRODUCTO QUIMICO

2.1. CONDICIONES DE DISPOSICIÓN:

5. ¿Los envases se colocan en?:
1. El suelo
2. Barandas de las paredes.
3. Bolsas plásticas, cajas u otro sistema de almacenaje.

2.1. CONDICIONES DE DISPOSICIÓN

6. ¿Los productos han sido "reenvasados"?

7. ¿Los envases se encuentran en buen estado (envases originales, sellados y sin fisuras ni roturas)?

8. ¿Se ha dispuesto un lugar específico para el depósito de los envases vacíos?: Especificar dónde se ubica ese sitio:

2.2. CONDICIONES DE ROTULACIÓN:

9. ¿Los envases cuentan con sus correspondientes etiquetas autoadhesivas identificando el tipo de químico almacenado?

10. ¿Los productos almacenados están vencidos?

11. ¿Las indicaciones de uso son legibles?

III. EQUIPO DE PROTECCIÓN PERSONAL Y EQUIPO APLICACIÓN DEL AGROQUÍMICO

12. ¿En algún espacio de la bodega se observa equipo de protección personal para la aplicación del agroquímico? a) Especificar tipo de equipo observado:

b) Indicar en qué parte de la bodega se coloca el equipo:

13. ¿En algún espacio de la bodega se observa equipo para la aplicación del agroquímico?

a) Especificar tipo de equipo observado:

b) Indicar en qué parte de la bodega se coloca el equipo:

\section{CONVIVENCIA CERCANA}

14. ¿En los alrededores de la bodega se observa?:

1. Niños o niñas jugando.

2. Animales como perros, gatos o gallinas.

3. Juguetes 0 algún otro artículo utilizado por niños para jugar.
Si (1) No (2) 
REFERENCIAS

1. Ferrero L. Costa Rica precolombina: arqueología, etnología, tecnología, arte. San José: Costa Rica; 1975.

2. Costa Rica. Fondo Nacional de Financiamiento Forestal y Centro Agronómico Tropical de Investigación y Enseñanza. Plan de intervención de la cuenca del río Morote con énfasis en la aplicación de pago por servicios ambientales. Proyecto "Plan de manejo de la microcuenca piloto para el proyecto y priorizar las intervenciones de la cuenca Morote". Informe final [en línea]. San José: FONAFIFO; 2013 [citado: 20 nov 2014]. Disponible en: http://www.fonafifo.go.cr/documentacion/biblioteca/consultorias_investigaciones/ce_psa_010.pdf

3. Organización Panamericana de la Salud. Efectos de los plaguicidas en la salud y el ambiente en Costa Rica. San José: Ministerio de Salud-OMS; 2003.

4. Vargas LP. Costa Rica, 1985-1997: liberalización y ajuste estructural del neoliberalismo. San José: EUNED, 2002.

5. Alvarado A, Navarro JR. Desarrollo, investigación y agricultura en Costa Rica. Agronomía Costarricense [en línea] 2005[citado: 20 Nov 2014];29(3):187-206. Disponible en: http://www.mag.go.cr/rev_agr/v29n03_187.pdf

6. Bach 0. Informe final: Agricultura y sostenibilidad. Vigésimo Informe Estado de la Nación en Desarrollo Humano Sostenible. Programa Estado de La Nación [en línea] 2013[citado 2 sep 2014].pp.1-23. Disponible en: http://www.estadonacion.or.cr/files/biblioteca_virtual/020/ambiente/Bach_Agricultura.pdf

7. Vega $S$, Rodríguez A, Ramírez, F. Intoxicaciones con plaguicidas en la zona del Pacífico Seco, Costa Rica. RevCostCiencMéd [en línea]. 1983 [citado 01 abr 2013]; 4(2):7-14. Disponible en: http://www.binasss.sa.cr/revistas/rccm/v4n2/art2.pdf

8. Cordero A, Ramírez G. Acumulamiento de cobre en los suelos del Pacíico Sur de Costa Rica y sus efectos detrimentales en la agricultura. AgronCostarric [en línea]. 1979 [citado: 2 feb 2015];3(1):63-78. Disponible en: http://www.mag.go.cr/rev_agr/N03n01_063.pdf

9. Pérez AG. Evaluación de las aguas de drenaje del sector de riego de Tamarindo y su influencia sobre el Parque Nacional Palo Verde. Cienc Tecnol. 2010; 26(1-2):71-86.

10. Organización Panamericana de la Salud (OPS)-Agencia Danesa para el Desarrollo Internacional (DANIDA). Situación epidemiológica de las intoxicaciones agudas por plaguicidas en el istmo centroamericano. Proyecto Aspectos Ocupacionales y Ambientales de la Exposición a Plaguicidas en el Istmo Centroamericano (PLAGSALUD). San José: OPS-DANIDA; 2002.

11. Trivelato $M$, Barboza G. Empleo de agroquímicos en Guanacaste: aspectos ambientales y exposición de la población. San José: [s.e.]; 1994.

12. Ramírez F, Chaverri F, De la Cruz E, Wesseling C, Castillo L, Bravo V. Importación de Plaguicidas en Costa Rica. Periodo 1977-2006. Heredia: Universidad Nacional-IRET; 2009. (Informes Técnicos, 6).

13. Andreu T. Costa Rica: Número uno del mundo en uso de agroquímicos. Noticias aliadas [en línea]. Jueves 1 nov 2011 [citado 01 dic 2013]. Disponible en: http:// www.noticiasaliadas.org/articles.asp?art=6449

14. Castillo $L E$, Ruepert $C$, Ramírez F, van Wendel $B$, Bravo V, De la Cruz E. Plaguicidas y otros contaminantes. Decimoctavo Informe Estado de la Nación en Desarrollo Humano Sostenible. San José: Programa Estado de la Nación; 2012.

15. Umaña $V$, Constela $M$, Taitelbaum $M$. Determinación de plaguicidas organoclorados en leche humana en Costa Rica; Informe de proyecto. San José; Universidad de Costa Rica-CONICIT; 1994.

16. Vargas M. Diagnóstico situacional de la malaria: el uso del DDT en Costa Rica. San José: OPS-OMS; 2001.

17. Vega $S$, Maroto I, Zúñiga $C$, Ramírez $F$. Actividad de las colinesterasas sanguíneas en una población de referencia costarricense. RevCostCiencMéd [en línea]. 1984 [citado 01 abr 2013]; 5(2):158-169. Disponible en: http://www.binasss. sa.cr/revistas/rccm/v5n2/art4.pdf.

18. Ramírez, V, Cuenca, P. Daño del ADN en trabajadoras bananeras expuestas a plaguicidas en Limón, Costa Rica. Rev Biol Trop [en línea]. 2002 [citado 01 abril 2013]; 50(2):507-518. Disponible en: http://www.scielo.sa.cr/scielo.php?script= sci_arttext\&pid=S0034-774442002000200010\&Ing.

19. Fieten KB, Kromhout $H$, Heederik D, van Wendel de Joode B. Pesticide Exposure and Respiratory Health of Indigenous Women in Costa Rica. Am J Epidemiol. 2009; (169):1500-1506.

20. Bravo V, Malavassi EC, Herrera G, Ramirez F. Uso de plaguicidas en cultivos agricolas como herramienta para el monitoreo de peligros en salud. Uniciencia [en línea]. 2013 [citado 28 ago 2014]; 27(1):351-376. Disponible en: www.revistas.una.ac.cr/uniciencia.
21. Cárdenas 0 , Silva E, Morales L, Ortiz J. Estudio epidemiológico de exposición a plaguicidas organofosforados y carbamatos en siete departamentos colombianos, 1998-2001. Biomédica [en línea]. 2005 [citado 28 ago 2014]; (25):170180. Disponible en: http://www.redalyc.org/articulo.oa?id=84325203.

22. Shanna C, Amanda Sue N, K.M. V N, Michele M. Prevalence of Self-Reported Diabetes and Exposure to Organochlorine Pesticides among Mexican Americans: Hispanic Health and Nutrition Examination Survey, 1982-1984. EnvironHealth Persp [en línea]. 2007 [citado 01abr 2013]; 115(12):1747-1752. Disponible en: http://www.jstor.org/stable/4540054.

23. Varona M, Cárdenas O, Crane C, Rocha S, Cuervo G, Vargas J. Alteraciones citogenéticas en trabajadoras con riesgo ocupacional de exposición a plaguicidas en cultivos de flores en Bogotá. Biomédica [en línea]. 2003 [citado 01 ago 2014];23 (2):141-152. Disponible en: http://www.revistabiomedica.org/index.php/biomedica/article/view/1206

24. Vinson F, Merbi M, Baldi I, Raynal H, Gamet-Payrastre L. La exposición a pesticidas y el riesgo de cáncer en la infancia: un meta-análisis de estudios epidemiológicos recientes. Occup Environ Med. 2011;68(9):694-702.

25. Machado AL, Butinof M, Sastre MA. Estilos de vida y percepción de riesgo en prácticas con plaguicidas. Poiésis [en línea]. 2012 [citado 01 abril 2013];(23):1-5. Disponible en: http://www.funlam.edu.co/revistas/index.php/poiesis/article/ view/343/321

26. Peres F, Moreira J, Rodrigues K, Claudio, L. Percepción de riesgo de los agricultores con respecto al uso de pesticidas en un área agrícola del Estado de Río de Janeiro, Brasil. Cienc Trab. 2007; 9(26):164-171.

27-Tinoco Ojanguren $R$, HalperinFrisch D. Investigación sobre plaguicidas y la salud en Chiapas: Lecciones para compartir. Capitulo 4. En: Rivero O, Rizo P, Guadalupe P, Gustavo O. Daños a la salud por plaguicidas. México DF: Consejo General de Salubridad- UNAM; 2000.

28. Mojica JF. Agroquímicos y representaciones sociales de la salud y la enfermedad en Colas de Gallo, Nicoya, Guanacaste [tesis]. San José: Universidad de Costa Rica-Escuela de Antropología y Sociología; 1998.

29. Araya L, Carazo E, Cartín V. Diagnóstico del uso de insecticidas utilizados contra Bemisiatabaci (Gennadius) en tomate y chile en Costa Rica. Manejo Integrado Plagas y Agroecol. 2005; 75:68-76.

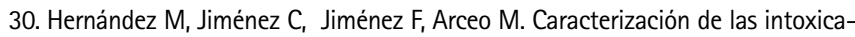
ciones agudas por plaguicidas: perfil ocupacional y conductas de uso de agroquímicos en una zona agrícola del estado de México, México. Rev. Int Contam Ambient. 2007; 23(4): 159-167.

31. Averallo E, Camarena L, von Glascoe C, Daesslé W. Percepción del riesgo en salud por exposición a mezclas de contaminantes: el caso de los valles agrícolas de Mexicali y San Quintín, Baja California, México. Rev. Fac. Nac. Salud Pública. 2009; 27(3): 291-301.

32. Sánchez K, Betanzos P. Aspectos socioeconómicos y culturales en el uso de agroquímicos y plaguicidas en los Altos de Morelos, México. Revista lbero americana de Economía Ecológica [en línea]. 2006 [citado 20 abril 2013]; 3:3347. Disponible en: http://www.redibec.org/IVO/rev3_03.pdf

33. Carey D. La Revolución Verde en Guatemala: fertilizante sintético, salud pública y autonomía económica en el Altiplano Maya. Mesoamérica. 2011; 32(53):32-73.

34. Castillo LE, Ruepert C, Bravo V, Fallas J. Vulnerabilidad de las aguas subterráneas a la contaminación por plaguicidas en Costa Rica. Heredia: Instituto Regional de Estudios en Sustancias Tóxicas-Universidad Nacional; 2005.

35. De la Cruz E, Pinnock M, Mena F, Echeverría S, Silva Z, Ruepert C, Ugalde R, et al. Impacto de los plaguicidas en el recurso hídrico de la zona baja de la cuenca del río Tempisque (Palo Verde) Costa Rica. Heredia: Instituto Regional de Estudios en Sustancias Tóxicas-Universidad Nacional; 2012.

36. Marín M, Ulloa P. Investigación sobre la identificación de efectos neurotóxicos en los trabajadores que utilizan agroquímicos en la comunidad de Moracia y Colas de Gallo Nicoya-Guanacaste. San José: ACEPESA; 1999.

37. Vega $S$, Rodríguez A y Ramírez F. Intoxicaciones con plaguicidas en la zona del Pacífico Seco, Costa Rica. Rev Cost Cienc Méd. 1983;4(2):7-14.

38. Moncada S. Evaluación del diseño de una biojardinera de flujo subsuperficial para el tratamiento de aguas grises en Zapote [tesis]. San José: Instituto Tecnológico de Costa Rica; 2011. 